Elsevier required licence: () 2016. This manuscript version is made available under the CC-BY-NC-ND 4.0 license http://creativecommons.org/licenses/by-nc-nd/4.0/ 


3

\title{
A differential evolution particle swarm optimizer for various types of multi-area economic dispatch problems
}

\author{
Mojtaba Ghasemi ${ }^{\mathrm{a}, *}$, Jamshid Aghaei ${ }^{\mathrm{a}}$, Ebrahim Akbari $^{\mathrm{b}}$, Sahand Ghavidel $^{\mathrm{c}}, \mathrm{Li} \mathrm{Li}^{\mathrm{c}}$

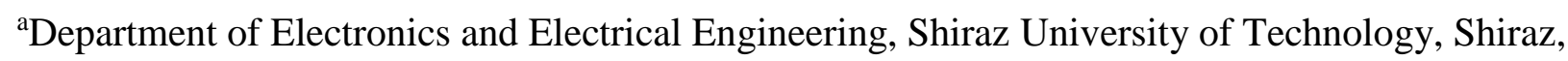 \\ Iran \\ ${ }^{\mathrm{b}}$ University of Isfahan, Isfahan, Iran \\ ${ }^{c}$ Faculty of Engineering and Information Technology, University of Technology, \\ Sydney, PO Box 123, Broadway, NSW 2007, Australia \\ ${ }^{*}$ Corresponding Author: M. Ghasemi, Department of Electronics and Electrical Engineering, \\ Shiraz University of Technology, Shiraz, Iran, phone: +98-917-3830620; e-mail: \\ mojtaba.ghasemi1365@yahoo.com.
}

Abstract- This paper proposes a new, efficient and powerful heuristic-hybrid algorithm using hybrid differential evolution (DE) and particle swarm optimization (PSO) techniques (DEPSO) designed to solve eight optimization problems with benchmark functions and the multi-area economic dispatch (MAED), reserve constrained MAED (RCMAED) and reserve constrained multi-area environmental/economic dispatch (RCMAEED) problems with reserve sharing in power systems operations. The proposed hybridizing sum-local search optimizer, entitled HSLSO, is a relatively simple but powerful technique. The HSLSO algorithm is used in this study for solving different MAED problems with non-smooth cost function. The effectiveness and efficiency of the HSLSO algorithm is first tested on a number of benchmark test functions. Experimental results shows the HSLSO has a better quality solution with the ability to converge for most of the tested functions. 
25 Keywords: Multi-area economic dispatch (MAED), reserve constrained multi-area economic

26 dispatch (RCMAED), reserve constrained environmental/economic dispatch (RCMAEED),

27 differential evolution particle swarm optimization (DEPSO).

\section{Introduction}

Economic load dispatch (ELD), optimal power flow (OPF) and optimal reactive power dispatch

31 (ORPD) nonlinear problems are some of the most important optimization problems in power

32 system operation and planning for allocating generation to the committed units [1-2]. They have

33 been resolved using many proposed optimization mathematical methods and modern heuristic

34 algorithms such as Hopfield neural network [1, 3], a modified harmony search algorithm

35 (MHSA) [4], genetic algorithm (GA) [5], real-coded GA (RCGA) [6], particle swarm optimization (PSO) [7], a proposed efficient scheme in [8] for clearing of energy and reserves in

37 multi-area markets, an immune algorithm (IA) with power redistribution [9], a new modified 38 differential evolution (MDE) [10], cuckoo search algorithm (CSA) [11], iteration PSO with time 39 varying acceleration coefficients [12], a hybrid DE algorithm based on PSO algorithm (DEPSO) 40 [13], PSO for dynamic ELD problem [14], information gap decision theory (IGDT) to help the 41 distribution network operators (DNOs) [15], risk-constrained self-scheduling of GenCos 42 generation companies (GenCos) optimizers [16], a new continuous method of quick group search 43 optimizer (QGSO) [17], imperialist competitive algorithms (ICA) for multi-objective OPF 44 problems [18], tribe-modified DE (Tribe-MDE) for solving multi-objective 45 environmental/economic dispatch (EED) [19], real coded chemical reaction algorithm (RCCRA) 46 [20], stochastic programming [21], firefly algorithm (FFA) for multi-objective EED considering 
47 wind power penetration [22], hybrid ICA algorithm with sequential quadratic programming 48 (HIC-SQP) [23], a new hybrid method for OPF problem with non-smooth cost functions [24], 49 combination of chaotic DE and QP (quadratic) [25], bacterial foraging algorithm (BFA) [26], 50 quantum PSO method [27], multi-objective CSA [28], a novel stochastic approach [29], DE 51 based dynamic decomposed strategy [30], a new hybrid algorithm for practical optimal dynamic 52 load dispatch (DLD) [31], self-adaptive learning charged system search algorithm (SALCSSA) 53 [32], solving stochastic OPF incorporating electric vehicles and offshore wind farm [33], 54 colonial competitive differential evolution (CCDE) technologies [34], and etc. The main 55 objective of ELD and OPF problems is the effective management of electrical energy generation 56 by minimizing the total fuel cost of power generation units of a single area, while satisfying 57 various system and operating constraints [35- 37]. The multi-area economic dispatch (MAED), 58 reserve constrained multi-area economic dispatch (RCMAED) and reserve constrained 59 environmental/economic dispatch (RCMAEED) problems [38-41] are an extension of ELD 60 problems in practical power systems, whose main objective is to determine the generation levels 61 and the power interchange between areas to minimize the operation cost (fuel cost function) of 62 thermal generating units in all areas of power systems while satisfying generating units power 63 limits, system power balance, and power transmission capacity constraints of network lines [4264 43]. combining the positive features of Constrained Particle Swarm, Generating Set Search, and 69 Complex (PGS-COM) for black-box optimization problems [47], a global review of PSO 
techniques for power systems [48], and DEPSO techniques for different engineering

71 optimization problems [49].

72 Different optimization algorithms have been proposed for solving the MAED problem of 73 electrical energy generations in the literature. Basu solved the MAED problem in different 74 practical power systems using artificial bee colony optimization (ABCO) [38] and teaching75 learning-based optimization (TLBO) [39] with prohibited operating zones, valve-point loading, 76 multiple fuels and tie line constraints considering transmission losses. Manoharan et al. [40] 77 solved MAED problems using evolutionary programming methods such as the DE, PSO, real78 coded genetic algorithm (RGA) and covariance matrix adapted evolution strategy (CMAES) for 79 4-, 10- and 120-unit power systems. Sudhakar et al. [41] applied Secant method to solve the 80 MAED problem. In [42], the evolutionary programming with Levenberg-Marquardt optimization 81 (EP-LMO) method is proposed to solve the MAED problem of a 10-unit power generation 82 system with multi-fuel options. In [43], a PSO-based method with the traditional solver GAMS is 83 proposed to solve the MAED problem of a large 120-unit power system. Sharma et al. solved 84 MAED and reserve constrained MAED (RCMAED) problems using various DE methods 85 enhanced with time-varying mutation [50] and the improved PSO method with a parameter 86 automation strategy having time varying acceleration coefficients (PSO_TVAC) [51]. Many 87 other heuristic search techniques have been proposed for solving economic dispatch problem, 88 such as a pattern search (PS) algorithm [52], an improved multi-objective PSO (MOPSO) for 89 solving multi-area environmental/economic dispatch (MAEED) problem [53], the direct search 90 method (DSM) [54], a new recurrent DE (RDE) method [55], PSO algorithm [56], a penalty 91 function-hybrid direct search method (PF-HDSM) for solving multi-area wind-thermal 92 coordination dispatch (MWCD) problem [57], enhanced direct search method (EDSM) [58], a 
93 novel approach based on harmony search (HS) algorithm [59], the optimality condition 94 decomposition (OCD) for solving multi-area dynamic economic dispatch (MA-DED) problem

95 [60], and different novel search approaches for solving multi-area generation scheduling such as 96 neural networks approach [61], traditional economic dispatch method [62], modification of

97 MAED [63], a new DE algorithm [64], an embedded multi-area optimal power flow (MA-OPF) 98 [65], a new proposed technique [66], a decomposition methodology [67, 68], a practical 99 approach [69], a generalized unified power flow controller [70], and evolutionary programming 100 [71].

101

\section{Multi-area economic dispatch problems}

103 The main purpose of the MAED optimization problem in power systems is to minimize the total 104 electrical energy generation cost for supplying loads of all areas with or without minimizing the 105 total pollutant emissions (such as $\mathrm{NO}_{\mathrm{x}}$ and $\mathrm{SO}_{2}$ emissions) while satisfying electrical power 106 balance constraints, electrical power generating limit constraints and transmission (tie-line) 107 capacity constraints. The objective functions of minimizing system operation (energy generation) 108 cost and pollutant emissions [38, 60] with valve point loading (VPL) effects and multiple fuel 109 options $[38,39]$ can be written in the following form:

$$
\operatorname{Min} \sum_{i=1}^{N}\left(F_{i}\left(P_{i}\right)\right)
$$

111 where: 
$1: F_{i}\left(P_{i}\right)= \begin{cases}a_{i 1} P_{i}^{2}+b_{i 1} P_{i}+c_{i 1}+\left|e_{i 1} \times \sin \left(f_{i 1} \times\left(P_{i, \text { min }}-P_{i}\right)\right)\right|, & \text { fuel1, } P_{i, \text { min }} \leq P_{i} \leq P_{i 1} \\ a_{i 2} P_{i}^{2}+b_{i 2} P_{i}+c_{i 2}+\left|e_{i 2} \times \sin \left(f_{i 2} \times\left(P_{i, \min }-P_{i}\right)\right)\right|, & \text { fuel } 2, P_{i 1} \leq P_{i} \leq P_{i 2} \\ \cdots & \text { fuel } k, P_{i k-1} \leq P_{i} \leq P_{i, \text { max }}\end{cases}$

$1132: N$ is the number of generation units.

$114 \quad 3: k$ is the fuel type.

$1154: P_{i}$ is the active power generation of the $i$-th unit, $P_{i, \min }$ and $P_{i, \max }$ are the minimum power 116 generation and maximum power generation limits of the $i$-th unit.

5: $a_{i k} P_{i}^{2}+b_{i k} P_{i}+c_{i k}$ is the quadratic fuel cost function for fuel type $k$ of the $i$-th unit.

6: $a_{i k}, b_{i k}$ and $c_{i k}$ are the fuel cost-coefficients for fuel type $k$ of the $i$-th unit.

120

7: $k$ for fuel type sinusoidal fuel cost function of VPL effectsthe is $\left|e_{i k} \times \sin \left(f_{i k} \times\left(P_{i, \min }-P_{i}\right)\right)\right|$

121 of the $i$-th unit.

122 8: $e_{i k}$ and $f_{i k}$ are the fuel cost-coefficients to model VPL effects for fuel type $k$ of the $i$ th unit.

Tie-line power transfer among all areas of the network plays a very important role in deciding the operating cost in multi-area networks. Taking into consideration the cost of active

125 power transmission through each tie-line of the power system, the final objective function of the

126 MAED optimization problem becomes [40, 50]: 
$\operatorname{Min} F_{T}=\operatorname{Min}\left(\sum_{i=1}^{N}\left(F_{i}\left(P_{i}\right)\right)+\sum_{j=1}^{M}\left(f_{j}\left(T_{j}\right)\right)\right)$

127 where, $M$ is the number of tie-lines among the network areas. $T_{j}$ is the power flow through the $j$ -

128 th tie-line, and $f_{j}$ is the cost coefficient function associated with the $j$-th tie-line among the

129 network areas.

130 - Minimizing the total pollutant emissions

$\operatorname{Min} \sum_{i=1}^{N}\left(E_{i}\left(P_{i}\right)\right)$

131 where:

132

$1: E_{i}\left(P_{i}\right)= \begin{cases}\alpha_{i 1} P_{i}^{2}+\beta_{i 1} P_{i}+\gamma_{i 1}, & \text { fuel } 1, P_{i, \text { min }} \leq P_{i} \leq P_{i 1} \\ \alpha_{i 2} P_{i}^{2}+\beta_{i 2} P_{i}+\gamma_{i 2}, & \text { fuel } 2, P_{i 1} \leq P_{i} \leq P_{i 2} \\ \cdots & \\ \alpha_{i k} P_{i}^{2}+\beta_{i k} P_{i}+\gamma_{i k}, & \text { fuel } k, P_{i k-1} \leq P_{i} \leq P_{i, \max }\end{cases}$

1332 : $\alpha_{i k} P_{i}^{2}+\beta_{i k} P_{i}+\gamma_{i k}$ is the quadratic pollutant emissions function for fuel type $k$ of the $i$-th unit.

$1343: \alpha_{i k}, \beta_{i k}$ and $\gamma_{i k}$ are the pollutant emissions coefficients for fuel type $k$ of the $i$-th unit.

\subsection{Constraints}

\subsubsection{Area real power balance}

138 The real power balance constraints of the system for area $q$ without consideration of network 139 losses can be given as [50, 53]: 


$$
\sum_{i=1}^{N_{q}}\left(P_{i}\right)=\left(P_{\text {Loadq }}+\sum_{j=1}^{M_{q}}\left(T_{q j}\right)\right)
$$

140 where $N_{q}$ is the number of real power generating units for the $q$-th area $(q=1,2, \ldots, M)$, and

$141 \quad P_{\text {Loadq }}$ is the active load demand in the $q$-th area and $M_{q}$ is the number of tie-lines connected to

142 the $q$-th area.

\section{$143 \quad$ 2.1.2. Unit power generating limit}

144 The active power output of units is restricted to their lower and upper limits as:

$$
P_{i, \min } \leq P_{i} \leq P_{i, \max }, \quad i=1, \ldots, N
$$

\subsubsection{Thermal generation unit's ramp-rate limits}

146 The ramp-rate limit constraints can be formulated as follows:

$$
\max \left(P_{i, \min }, P_{i}^{0}-D R_{i}\right) \leq P_{i} \leq \min \left(P_{i, \max }, P_{i}^{0}+U R_{i}\right)
$$

147 where $P_{i}^{0}$ is the previous output real power of the $i$-th generation unit, and the $D R_{i}$ and $U R_{i}$ are 148 the down and up ramp rate-limits of the $i$-th thermal generation unit, respectively.

\subsubsection{Prohibited operating zones}

150 A performance curve, i.e. input-output power generation curve, of a thermal generating unit with

151 prohibited operating zones (POZ) has discontinuities due to physical operational limitations of

152 the generator such as faults in the machines themselves or in the associated auxiliaries [38-39].

153 The discontinuous input-output power range of a generator can be formulated as follows [50]: 


$$
P_{i} \in\left\{\begin{array}{l}
P_{i, \min } \leq P_{i} \leq P_{i 1}^{l} \\
\cdots \\
P_{i k-1}^{u} \leq P_{i} \leq P_{i k}^{l} \\
\cdots \\
P_{i z_{i}}^{u} \leq P_{i} \leq P_{i}^{\max }
\end{array}\right.
$$

154 where $z_{i}$ is the number of prohibited zones in the input-output power curve of $i$-th generator, $k$ is

155 the index of prohibited zone of $i$-th generator, $P_{i k}^{l}$ and $P_{i k}^{u}$ are the lower and upper limits of $k$-th 156 prohibited operating zone of the $i$-th generation unit, respectively.

\section{$157 \quad$ 2.1.5. Tie-line power transfer limits}

158 The tie-line real power flow (economic flow) from the $q$-th area to the $j$-th area $\left(T_{q j}\right)$ should be 159 between the limits of tie-line power transfer capacity [50].

$T_{q j, \min } \leq T_{q j} \leq T_{q j, \max }, \quad j=1,2, \ldots, M_{q}$

In the $q$-th area of a power system, a spinning reserve is set aside in each region for the contingency prerequisite of that region (required spinning reserve) and reserve contribution, the

164 necessary spinning reserve is fulfilled through multi area reserve sharing [53]:

$$
\sum_{i=1}^{N_{q}} S_{i q} \geq S_{q, r e q}+\sum_{k . k \neq q} R C_{q k}, k=1,2, \ldots, M_{q}
$$


165 where $\sum_{i=1}^{N_{q}} S_{i q}$ is the reserve prevailing on all the generation units of $q$-th area, and can be

166 considered as, $\sum_{i=1}^{N_{q}}\left(P_{i}^{\max }-P_{i}\right), S_{q, r e q}$ is the prerequisite spinning reserve in the $q$-th area, and $167 R C_{q k}$ is the reserve contributed from $k$-th area to $q$-th area.

\subsubsection{Tie-line power transfer restrictions with contributed reserve}

169 The tie-line power transfer restrictions with allowing for contributed reserve $R C_{q k}$ is as follows $170 \quad[53]:$

$$
T_{q j, \min } \leq T_{q j}+R C_{q j} \leq T_{q j, \max }, \quad j=1,2, \ldots, M_{q}
$$

172 It is worth declaring that the control variables are self-constrained. The hard constraints of real

173 power balance can be combined with the objective function as quadratic penalty expressions. For

174 that reason, the objective function of different MAED optimization problems can be presented as 175 follows:

$$
\operatorname{Min} F_{T}=\operatorname{Min}\left(\sum_{i=1}^{N}\left(F_{i}\left(P_{i}\right)\right)+\sum_{j=1}^{M}\left(f_{j}\left(T_{j}\right)\right)+\phi \times \sum_{i=1}^{N}\left(E_{i}\left(P_{i}\right)\right)+\lambda \times\left(\sum_{i=1}^{N}\left(P_{i}\right)-P_{\text {Load }}\right)\right)
$$

176 where $\phi$ is an appropriate value which will be nominated by the user for the RCMAEED problem,

$177 \lambda$ is the penalty factor and $P_{\text {Load }}$ is the total active load demand in the whole area.

\section{Hybrid DEPSO techniques}


3.1 .

Original

181

\section{differential evolution}

The DE algorithm is one of the population-based optimization algorithms, which was first proposed by Storn and Price [44-45] and has been widely applied to optimization problems in the power systems and engineering [49].

The steps for implementing original DE algorithm are as follows [72-73]:

Step 1: Initial population: A population of $N_{P}$ initial solutions randomly distributed in the $D$ dimensional search space of the optimization problem, are initiated.Each individual is generated as follows:

$X_{j, i}^{\text {Iter }=0}=X_{j, \min }+\operatorname{rand}(0,1) \times\left(X_{j, \max }-X_{j, \min }\right) ;$

$j=1,2, \ldots, D, i=1,2, \ldots, N_{P}$

where rand $(0,1)$ is a random number between 0 and 1 .

Step 2: Mutation operator: In mutation step, for each individual $X_{i}$ (target vector) of the new population, three different individuals $X_{r 1}, X_{r 2}$, and $X_{r 3}(r 1 \neq r 2 \neq r 3 \neq i)$ are pseudo-randomly extracted from the population to generate a new vector as:

$Z_{i}=X_{r 1}+F \times\left(X_{r 2}-X_{r 3}\right)$

where $F \in[0,2]$ is a uniformly distributed random number which controls the length of the population exploration vector $\left(X_{r 2}-X_{r 3}\right)$.

Step 3: Crossover operator: After mutation step, the crossover operator, according to the following equation, is applied on the mutation vector $Z_{i}$ and the vector $X_{i}$ to generate the trial vector $U_{i}$, for increasing the population diversity of the mutation vector. 


$$
\begin{gathered}
U_{j, i}= \begin{cases}Z_{j, i}, & \text { if } \operatorname{rand}_{i, j}(0,1) \leq C R \\
X_{j, i}, & \text { otherwise }\end{cases} \\
j=1,2, \ldots, D, i=1,2, \ldots, N_{P} .
\end{gathered}
$$

where $C R \in[0,1]$ is known as the crossover rate which is a constant.

Step 4: Selection operator: The selection process is repeated for each pair of target/trial vectors using the evaluation function $F\left(U_{i}\right)$ to compare with the evaluation function value $F\left(X_{i}\right)$, and the better one will be selected to be a member of the DE population generation for the next iteration $\left(X_{i}^{\text {Iter }+1}\right)$.

Original

\section{particle swarm optimization (classical PSO with the Gbest model)}

205

The PSO algorithm is one of the population-based metaheuristic algorithms, a powerful tool in 206 search and optimization [48], which is based on the swarm intelligence theory and was first proposed by Kennedy and Eberhart [46]. In this stochastic optimization algorithm, each individual in the swarm population, called particle, represents one solution of the optimization

problem. The $i$-th particle, $X_{i}^{\text {Iter }}$ is moved by a velocity $\left(V_{j, i}^{\text {Iter }+1}=\left\{V_{1, i}^{\text {Iter }+1}, V_{2, i}^{\text {Iter }+1}, \ldots, V_{D, i}^{\text {Iter }+1}\right\}\right)$ which is calculated by three components: social component $\left(\right.$ Gbest $\left._{j, i}^{\text {Iter }}-X_{j, i}^{\text {Iter }}\right)$, cognitive component

be stated as follows [46-47]:

$$
\begin{aligned}
& V_{j, i}^{\text {Iter }+1}=\omega \times V_{j, i}^{\text {Iter }}+c 1 \times \operatorname{rand} 1(0,1) \times\left(\text { Pbest }_{j, i}^{\text {Iter }}-X_{j, i}^{\text {Iter }}\right) \\
& +c 2 \times \operatorname{rand} 2(0,1) \times\left(\text { Gbest }_{j, i}^{\text {Iter }}-X_{j, i}^{\text {Iter }}\right)
\end{aligned}
$$

$$
X_{j, i}^{\text {Iter }+1}=X_{j, i}^{\text {Iter }}+V_{j, i}^{\text {Iter }+1}
$$


where Pbest $_{i}^{\text {Iter }}=\left\{\right.$ Pbest $_{1, i}^{\text {Iter }}$, Pbest $_{2, i}^{\text {Iter }}, \ldots$, Pbest $\left._{D, i}^{\text {Iter }}\right\}$ denotes the best position that is found so far

by the $i$-th particle, Gbest ${ }_{i}^{\text {Iter }}=\left\{\right.$ Gbest $_{1, i}^{\text {Iter }}$, Gbest $\left._{2, i}^{\text {Iter }}, \ldots, G b e s t_{D, i}^{\text {Iter }}\right\}$ is the global best position that is

found by all of the particles in the swarm. The constants $c 1$ and $c 2$ are the so-called acceleration 217 factors usually chosen to be 2 , and the constant $\omega$ is the inertia weight.

\subsection{DEPSO1} with Gbest model algorithms is proposed by Zhang and Xie. In the hybrid algorithm, DE

222 along with the evolution and further improving the Pbest of PSO algorithm. The hybrid 223 DEPSO1 algorithm is applied to a set of the generalized Griewank function, the Rosenbrock

224 function and the generalized Rastrigrin function, and the results show the better performance of 225 the DEPSO1 algorithm in comparison with DE and PSO algorithms. The DE operators are given 226 by [74]:

$$
\begin{aligned}
& Z_{i}=\text { Xbest }(\text { Gbest })+F \times\left(\text { Pbest }_{r 1}-\text { Pbest }_{r 2}+\text { Pbest }_{r 3}-\text { Pbest }_{r 4}\right) \\
& U_{j, i}=\left\{\begin{array}{l}
Z_{j, i}, \text { if rand } \\
\text { Pbest }_{j, i}, \text { otherwise. }
\end{array}\right.
\end{aligned}
$$

\section{3.4. DEPSO2}

228 A new hybrid algorithm using DE/mid-to-better/1/bin and PSO-cf algorithm was proposed by

229 Hao et al. [75], which can maintain the diversity of swarm and enhance the ability of global 230 (Gbest) and local (Pbest) search using improved particle positions. The experimental results of 231 testing the DEPSO2 algorithm for benchmark test functions showed the effectiveness of the 232 hybrid algorithm. The DE and PSO operators of DEPSO2 are selected as follows [75]: 
$\left.\begin{array}{l}V_{j, i}^{\text {Iter }+1}=\omega \times V_{j, i}^{\text {Iter }}+c 1 \times \operatorname{rand} 1(0,1) \times\left(\text { Pbest }_{j, i}^{\text {Iter }}-X_{j, i}^{\text {Iter }}\right) \\ +c 2 \times \operatorname{rand} 2(0,1) \times\left(\text { Gbest } t_{j, i}^{\text {Iter }}-X_{j, i}^{\text {Iter }}\right) \\ Z_{j, i}^{\text {Iter }+1}(\mathrm{PSO})=X_{j, i}^{\text {Iter }}+V_{j, i}^{\text {Iter }+1} \\ Z_{j, i}^{\text {Iter }+1}(\mathrm{DE})=\left(\frac{X_{j, r 1}^{\text {Iter }}+X_{j, i}^{\text {Iter }}}{2}\right) \\ +F \times\left(X_{j, r 1}^{\text {Iter }}-X_{j, i}^{\text {Iter }}+X_{j, r 2}^{\text {Iter }}-X_{j, r 3}^{\text {Iter }}\right)\end{array}\right\} \rightarrow \mathrm{DSO}$

233

$U_{j, i}= \begin{cases}Z_{j, i}^{\text {Iter }+1}(\mathrm{DE}), & \text { if } \operatorname{rand}_{i, j}(0,1) \leq C R \\ Z_{j, i}^{\text {Iter }+1}(\mathrm{PSO}), & \text { otherwise. }\end{cases}$

\section{$234 \quad 3.5 . \quad$ DEPSO3 [76]}

235 In [76], $\mathrm{Xu}$ et al. also proposed a DE mixed with particle swarm intelligence, called DE-SI 236 method (which is called DEPSO3 in this paper). The experimental results indicate that, for most

237 benchmark problems, the DE-SI hybrid algorithm keeps the most rapid convergence rate and 238 obtains the global optima compared with DE and PSO algorithms. As proposed by Xu et al. [76], 239 the mutation and crossover operators of DE algorithm are as follows:

$X_{j, i}^{\text {Iter }+1}=\left\{\begin{array}{l}X_{j, i}^{\text {Iter }}+c 2 \times \operatorname{rand} 1(0,1) \times\left(\text { Gbest }_{j}^{\text {Iter }}-X_{j, i}^{\text {Iter }}\right) \text { if } \operatorname{rand} 2(0,1) \leq C R \\ X_{j, i}^{\text {Iter }}, \text { otherwise. }\end{array}\right.$

$240 \quad$ 3.6. DEPSO4

241 In reference [77], Liu et al. proposed a new hybrid-optimized cultural algorithm based on

242 DE/rand/1/bin and PSO algorithms (namely DEPSO4). The simulation results of [77] showed

243 that the proposed algorithm had the best solution and performed better for most test functions.

244 The algorithm formula is given by [77]: 


$$
X_{j, i}^{\text {Iter }+1}=\left\{\begin{array}{l}
X_{j, r 1}^{\text {Iter }}+F \times\left(X_{j, r 2}^{\text {Iter }}-X_{j, r 3}^{\text {Iter }}\right)+V_{j, i}^{\text {Iter }+1} \text { if } \operatorname{rand}(0,1) \leq C R \\
X_{j, i}^{\text {Iter }}+V_{j, i}^{\text {Iter }+1}, \text { otherwise. }
\end{array}\right.
$$

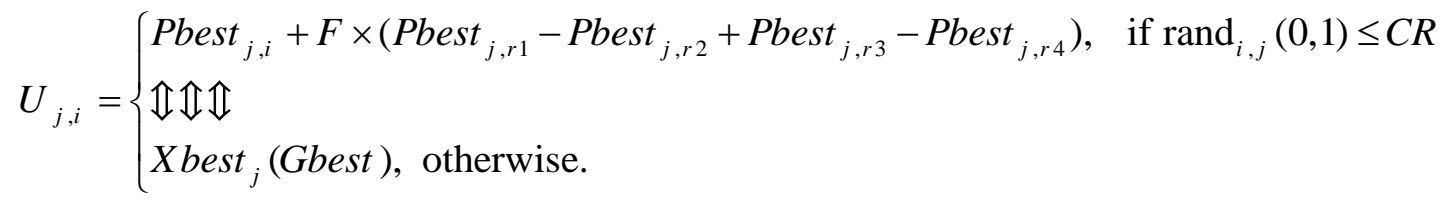

\section{3.7.2. IDEPSO3}

258 According the obtained experimental results from the DEPSO3 [76] algorithm for benchmark 259 functions which are summarized in Tables 1-3, it is seen that the DEPSO3 algorithm is weak for 260 specific problems such as third benchmark function. In the improved version of DEPSO3, called 261 IDEPSO3, in (21), the role of Gbest was replaced with Pbest and for rand $(0,1)>C R$, the global 262 best (Gbest) was used instead of $X_{i}$ value. The population move model of IDEPSO3 is shown 263 as follows: 
$X_{j, i}^{\text {Iter }+1}=\left\{\begin{array}{l}X_{j, i}^{\text {Iter }}+F \times\left(\text { Pbest }_{j, i}^{\text {Iter }}-X_{j, i}^{\text {Iter }}\right) \text { if } \operatorname{rand}(0,1) \leq C R \\ \text { Gbest }_{j}^{\text {Iter }}, \text { otherwise. }\end{array}\right.$

\subsubsection{IDEPSO4}

266 With a simple change and no extra cost in population move equation (22) of DEPSO4 algorithm, 267 a more powerful improved hybrid algorithm can be achieved, called IDEPSO4. The population 268 move equation of IDEPSO4 is described as follows:

269

$X_{j, i}^{\text {Iter }+1}=\left\{\begin{array}{l}\text { Pbest }_{j, r 1}+F \times\left(\text { Pbest }_{j, r 2}-\text { Pbest }_{j, r 3}\right)+V_{j, i}^{\text {Iter }+1}, \\ \text { Pbest }_{j, i}+\operatorname{rand}(0,1) \times V_{j, i}^{\text {Iter }+1}, \text { otherwise }\end{array}\right.$

3.8. The proposed hybridizing sum-local search optimizer (HSLSO)

271 In this hybrid sum-local search optimizer (HSLSO), the sum differential evolution with particle

272 swarm optimizer (SDEPSO) based DEPSO2 [75] is used along with the local (Pbest) optimal

273 value in DE crossover operator. We can use the (19) and (20) of DEPSO2 for HSLSO algorithm:

$U_{j, i}= \begin{cases}\frac{Z_{j, i}^{\text {Iter }+1}(\mathrm{DE})+Z_{j, i}^{\text {Iter }+1}(\mathrm{PSO})}{2}, & \text { if } \operatorname{rand}_{i, j}(0,1) \leq C R \\ \text { Pbest }_{j, i}, \text { otherwise. } & \end{cases}$

274 Fig. 1 shows the flowchart of the proposed HSLSO algorithm. 


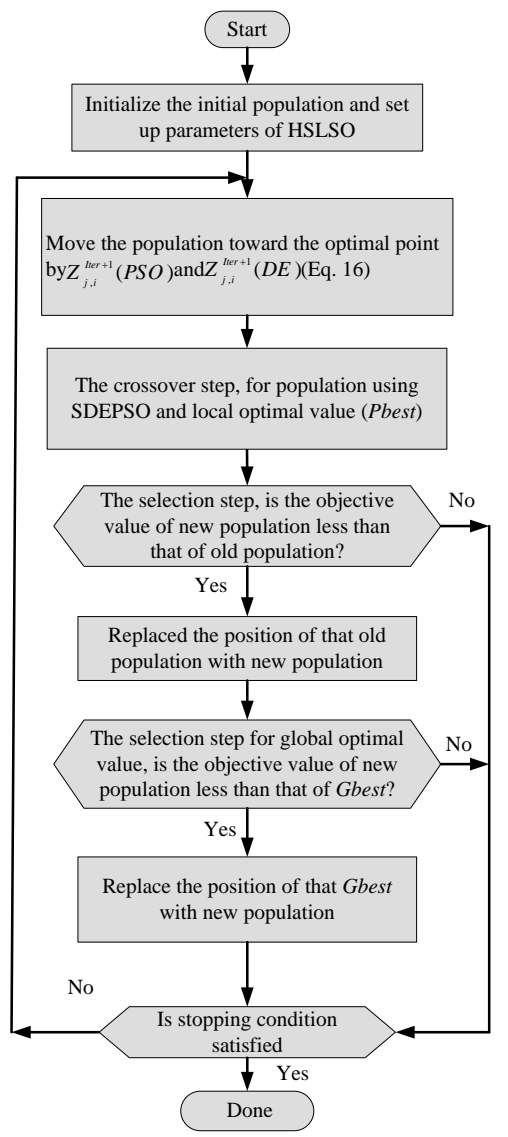

276 Fig. 1. Flowchart of HSLSO algorithm.

277

278

279 4. Performance test of HSLSO on benchmark functions

280 In the experiments, several multi-modal and uni-modal benchmark test functions were chosen for

281 testing the HSLSO and comparing it with other hybrid DEPSO algorithms. All of the benchmark

282 functions are listed as follows:

1) Sphere function, $f_{1}=\sum_{j=1}^{D} x_{j}^{2}$ with $x_{j} \in[-100,100]$ and $f(x)=0$.

2) Quadric function, $f_{2}=\sum_{j=1}^{D}\left(\sum_{i=1}^{j} x_{i}\right)^{2}$ with $x_{j} \in[-100,100]$ and $f(x)=0$. 
3) Rosenbrock's function, $f_{3}=\sum_{j=1}^{D-1}\left(100\left(x_{j}^{2}-x_{j+1}\right)^{2}+\left(x_{j}-1\right)^{2}\right)$ with $x_{j} \in[-2.048,2.048]$ and $f(x)=0$.

4) Rastrigin's function, $f_{4}=\sum_{j=1}^{D} x_{j}^{2}\left(x_{j}^{2}-10 \cos \left(2 \pi x_{j}\right)+10\right)$ with $x_{j} \in[-5.12,5.12]$ and $f(x)$ $=0$.

289

5) Noncontinuous Rastrigin's function,

290

$$
f_{5}=\sum_{j=1}^{D} y_{j}^{2}\left(y_{j}^{2}-10 \cos \left(2 \pi y_{j}\right)+10\right)
$$

$$
y_{j}=\left\{\begin{array}{ll}
x_{j}, & \left|y_{j}\right|<\frac{1}{2} \\
\frac{\operatorname{round}\left(2 x_{j}\right)}{2}, & \left|y_{j}\right| \geq \frac{1}{2}
\end{array} \quad \text { for } j=1,2, \ldots, D \quad \text { with } x_{j} \in[-5.12,5.12] \text { and } f(x)=0 .\right.
$$

6) Ackley's function,

$$
f_{6}=-20 \exp \left(-0.2 \sqrt{\frac{1}{D} \sum_{j=1}^{D} x_{j}^{2}}\right)
$$

$$
-\exp \left(\frac{1}{D} \sum_{j=1}^{D} \cos \left(2 \pi x_{j}\right)\right)+20+e
$$

7) Weierstrass function,

295

$$
f_{7}=\sum_{j=1}^{D}\left(\sum_{k=0}^{k \max }\left[a^{k} \cos \left(2 \pi b^{k}\left(x_{j}+0.5\right)\right)\right]\right)
$$

$-D \sum_{k=0}^{k \max }\left[a^{k} \cos \left(\pi b^{k}\right)\right], a=0.5 \quad b=3 \quad k \max =20$.

with $x_{j} \in[-0.5,0.5]$ and $f(x)=0$.

8) Exponential function, $f_{8}=-\exp \left(-0.5 \sum_{j=1}^{D} x_{j}^{2}\right)$ with $x_{j} \in[-1.0,1.0]$ and $f(x)=-1$. 
297 The Mean, Best and standard deviation (Std) index values for the hybrid DEPSO algorithms of 298 each benchmark test function over 30 runs with optimization variable dimension equal to 10, 50 299 and $100(10-D, 50-D$, and 100-D) are presented in Tables 1, 2, and 3, respectively, which shows 300 that the HSLSO algorithm is statistically superior to most of the other hybrid DEPSO and 301 IDEPSO algorithms. The used parameter values for all hybrid DEPSO algorithms in the 302 experiments are selected as: the initial population size $N_{P}=2.5 \times D$, number of iterations Iter $=$ $30320,000, F=2 \times r$ and $(0,1)$ for the hybrid algorithms proposed in other references [74-77] and $F=$ $3042 \times(0.5$-rand $(0,1))$ for the hybrid algorithms proposed in this paper, and crossover rate $C R=0.5$. 305 The results indicate that HSLSO algorithm is suitable for solving the employed test function 306 optimizations with better performance than most of other algorithms for most of the test 307 functions; particularly for larger dimensions, the hybrid algorithm responds very well. For five of 308 the benchmark test functions including Sphere, Rastrigin's, Noncontinuous Rastrigin's , 309 Weierstrass, and Exponential test functions, HSLSO algorithm obtained the global optimum 310 solution with Mean $=0.0$, and $\mathrm{Std}=0.0$. And also, a simple comparison of HSLSO algorithm with

311 two standard PSO algorithms in the recent literature is given in Appendix.

312 Table 1. Comparison of the simulation results for $D=10$.

\begin{tabular}{|c|c|c|c|c|c|c|c|c|c|}
\hline Function & Index & \multicolumn{8}{|c|}{ Algorithms } \\
\hline \multirow[t]{2}{*}{$f_{1}$} & Mean & 0.0 & 0.0 & 0.0114 & $5.6213 e+03$ & 58.8331 & 0.2448 & $1.5709 \mathrm{e}-237$ & 0.0 \\
\hline & Std & 0.0 & 0.0 & 0.0362 & $1.8152 \mathrm{e}+03$ & 74.5253 & 0.1917 & 0.0 & 0.0 \\
\hline \multirow[t]{2}{*}{$f_{2}$} & Mean & $3.2576 \mathrm{e}-123$ & $1.9956 \mathrm{e}-191$ & 642.2169 & $6.8059 \mathrm{e}+03$ & 757.8297 & 8.0906 & $2.5901 \mathrm{e}-044$ & 0.0 \\
\hline & Std & $8.2012 \mathrm{e}-123$ & 0.0 & 773.0697 & $1.5283 \mathrm{e}+03$ & $1.3265 \mathrm{e}+03$ & 4.4774 & $4.9682 \mathrm{e}-044$ & 0.0 \\
\hline$f_{3}$ & Best & 0.0 & $8.1964 \mathrm{e}-010$ & 3.3318 & 210.4062 & 5.4669 & 2.3497 & $1.2787 \mathrm{e}-013$ & $7.6395 \mathrm{e}-020$ \\
\hline \multirow{3}{*}{$f_{4}$} & Best & 0.0 & 0.0 & 1.9599 & 78.3083 & $2.6083 \mathrm{e}-06$ & $1.8623 \mathrm{e}-06$ & 0.0 & $\mathbf{0 . 0}$ \\
\hline & Mean & 3.1358 & 0.392 & 42.5274 & 203.0712 & 8.9173 & $5.0388 \mathrm{e}-05$ & 0.0 & 0.0 \\
\hline & Std & 4.8183 & 0.6852 & 76.9012 & 68.8529 & 8.7947 & $8.0750 \mathrm{e}-05$ & 0.0 & 0.0 \\
\hline \multirow{3}{*}{$f_{5}$} & Best & 0.0 & 0.0 & 9.0625 & 74.7382 & $8.2893 \mathrm{e}-07$ & $6.9180 \mathrm{e}-07$ & 0.0 & 0.0 \\
\hline & Mean & 0.0 & 0.5 & 69.9063 & 175.2241 & 6.5444 & $2.1334 \mathrm{e}-05$ & 0.0 & 0.0 \\
\hline & Std & 0.0 & 0.7071 & 68.3498 & 60.0366 & 15.8 & $1.9761 \mathrm{e}-05$ & 0.0 & 0.0 \\
\hline
\end{tabular}




\begin{tabular}{|c|c|c|c|c|c|c|c|c|c|}
\hline & Mean & $2.1 \mathrm{e}-04$ & $6.4277 \mathrm{e}-06$ & 5.7135 & 10.9352 & 1.7869 & 0.4605 & 0.0 & 0.0 \\
\hline & Std & $6.6408 \mathrm{e}-04$ & $2.0326 \mathrm{e}-05$ & 1.4247 & 0.687 & 1.1844 & 0.0676 & 0.0 & 0.0 \\
\hline \multirow{3}{*}{$f_{8}$} & Best & -1.0 & -1.0 & -1.0 & -0.8345 & -1.0 & -1.0 & -1.0 & -1.0 \\
\hline & Mean & -1.0 & -1.0 & -1.0 & -0.7446 & -1.0 & -1.0 & -1.0 & -1.0 \\
\hline & Std & 0.0 & 0.0 & 0.0 & 0.0493 & 0.0 & 0.0 & 0.0 & 0.0 \\
\hline
\end{tabular}

313

314

315 Table 2. Comparison of the simulation results for $D=50$.

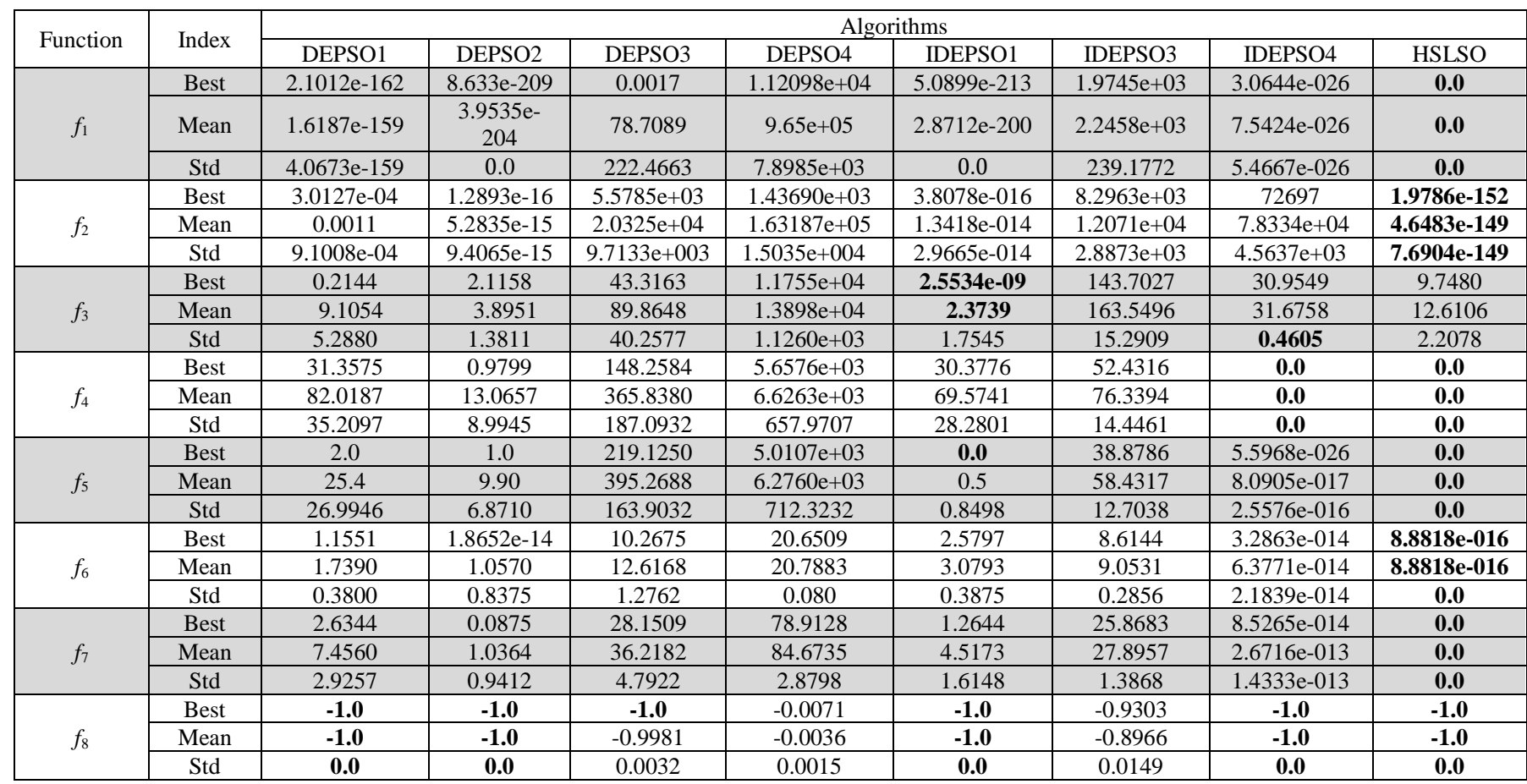

316

317 Table 3. Comparison of the simulation results for $D=100$.

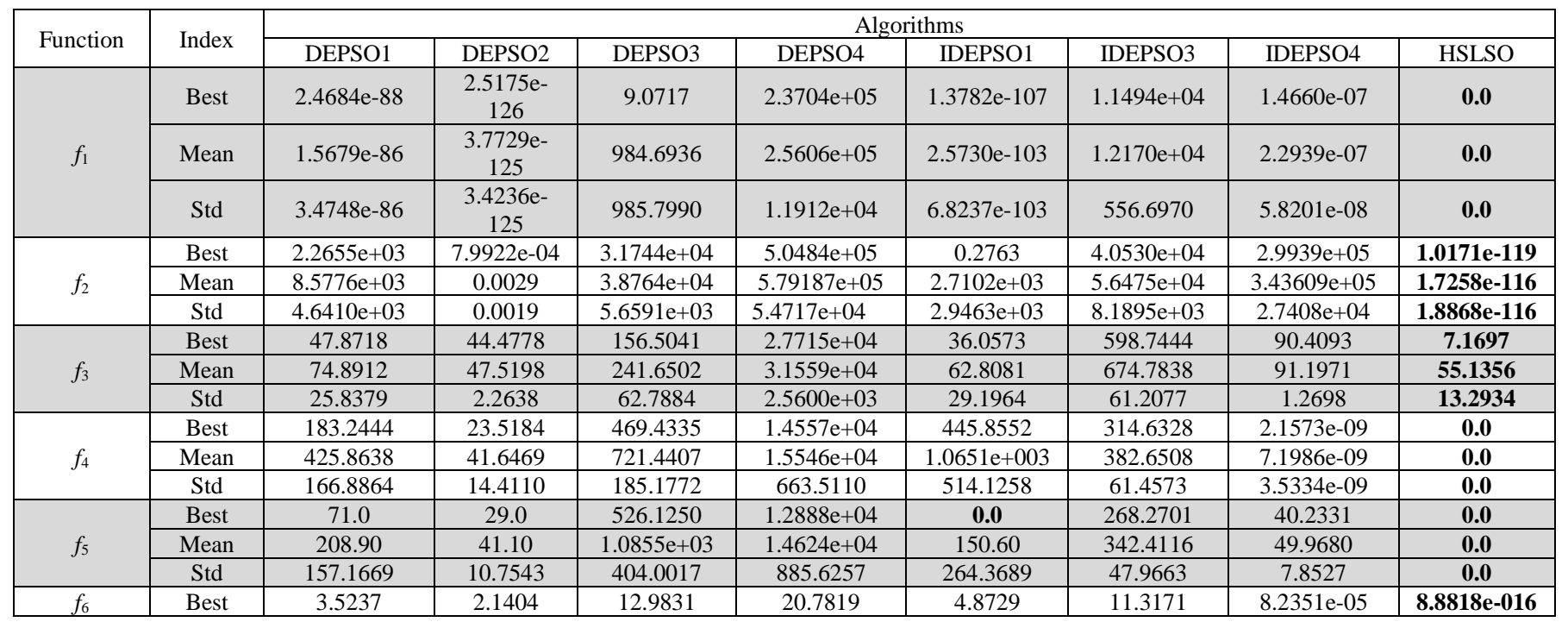




\begin{tabular}{|c|c|c|c|c|c|c|c|c|c|}
\hline & Mean & 5.1746 & 2.4650 & 14.9261 & 20.9181 & 8.7829 & 11.8329 & $9.1188 \mathrm{e}-05$ & $8.8818 \mathrm{e}-016$ \\
\hline & Std & 1.4038 & 0.3748 & 0.9275 & 0.0645 & 3.5860 & 0.3432 & $5.5450 \mathrm{e}-06$ & 0.0 \\
\hline \multirow{3}{*}{$f_{7}$} & Best & 28.6819 & 6.5584 & 68.6311 & 170.0688 & 17.5815 & 71.8828 & 0.1321 & 0.0 \\
\hline & Mean & 35.4578 & 9.1751 & 82.8843 & 177.4577 & 21.9614 & 75.8958 & 0.1410 & 0.0 \\
\hline & Std & 4.4921 & 2.3480 & 8.9549 & 3.6109 & 3.7215 & 2.1531 & 0.0086 & 0.0 \\
\hline \multirow{3}{*}{$f_{8}$} & Best & -1.0 & -1.0 & -0.9980 & $-1.3336 \mathrm{e}-05$ & -1.0 & -0.5856 & -1.0 & -1.0 \\
\hline & Mean & -1.0 & -1.0 & -0.9140 & $-4.6770 \mathrm{e}-06$ & -1.0 & -0.5458 & -1.0 & -1.0 \\
\hline & Std & 0.0 & 0.0 & 0.0817 & $3.7485 \mathrm{e}-06$ & 0.0 & 0.0298 & 0.0 & 0.0 \\
\hline
\end{tabular}

318

319 5. Implementation of the proposed algorithm for MAED optimization

320 In this section, the method of implementing the novel HSLSO algorithm for solving the MAED

321 optimization in different power systems will be described. The process of the HSLSO can be

322 summarized as follows:

323 Step 1: Set the parameters $F, C R, N_{P}$, Iter $\max , c 1$ and $c 2$, and call out the needed information for testing

324 the system units, such as $a_{i k}, b_{i k}, c_{i k}, e_{i k}, f_{i k}, P_{i, \min }, P_{i, \max }, D R_{i}, U R_{i},\left(i=1: N_{P}\right)$ with the total active load

325 demand $P_{D q}$.

326 Step 2: Produce the initial population matrix $\left[X_{0}\right]$ with the following equations:

$$
\begin{aligned}
& P_{i}^{L}=\max \left\{P_{i, \min }, P_{i}^{0}-D R_{i}\right\}, \\
& P_{i}^{U}=\min \left\{P_{i, \max }, P_{i}^{0}+U R_{i}\right\}, \\
& P_{i}^{L} \leq P_{i} \leq P_{i}^{U},
\end{aligned}
$$

$$
\left[X_{j, i}^{0}\right]_{D \times N_{p}}=\left[P_{i}^{L}+\operatorname{rand}_{j, i}(0,1) \times\left(P_{i}^{U}-P_{i}^{L}\right)\right]_{D \times N_{p}} .
$$

328 Step 3: Calculate the objective function $F\left(P_{i}\right)$ of MAED optimization problem by imposing the real

329 power limit constraint and real power generation-demand balance for every available solution in the 330 initial population of the algorithm. The penalty functions [24][ 59] have been used most often for the 331 constraint-handling procedure of MAED problems and are also used in HSLSO.

332 Step 4: Produce the new population of HSLSO using velocities of population, mutation, crossover and 333 selection operators. 
334 Step 5: Calculate the objective function $F\left(P_{i}\right)$ of MAED optimization problem.

335 Step 6: Repeat steps 4 and 5 till reaching the maximum number of iterations.

\section{Simulation results}

337 To evaluate the performance, effectiveness and efficiency of the hybrid DEPSO algorithms, they

338 have been applied to MAED problems in three test power systems. These are a two-area system 339 with four generating units, a four-area system with sixteen generating units, and a two-area 340 system with forty generating units. All of the algorithms have been implemented in MATLAB 3417.0 on a PC.

\subsection{Test system 1: A two-area system with four generating units}

344 The test system 1 is a two-area test system with four generating units (a small-scale system) 345 whose details are available in Ref. [54, 61], and active tie-line flow limit and active load demand 346 are set at $200 \mathrm{MW}$ and $1120 \mathrm{MW}$, respectively. The total load demand in area 1 ( $P_{1}$ and $P_{2}$ units) 347 is $70 \%$ and in area $2\left(P_{3}\right.$ and $P_{4}$ units $)$ is 30\% [40, 50]. The experimental results of DEPSO 348 algorithms for the test system 1 with three different crossover rates $C R=0.3,0.5$, and 0.7 are 349 tabulated in Table 4 with $N_{P}=20$. The simulation results show that the DEPSO1 for $C R=0.7$, 350 DEPSO2 for $C R=0.3$ and 0.5, IDEPSO1 for $C R=0.7$, and HSLSO for $C R=0.5$ and 0.7 , find the 351 best solutions with standard deviation of the best results obtained for 30 trials equal to zero for a 352 small-scale system. The convergence characteristics of DEPSO algorithms for the best solution 353 of $C R=0.5$ are plotted in Fig. 2. It can be seen that HSLSO algorithm converges faster than the 354 other DEPSO algorithms for this test system. 
359 Table 4. Comparison of the simulation results for test system 1 with different crossover rates.

\begin{tabular}{|c|c|c|c|c|c|c|c|c|c|}
\hline \multirow{2}{*}{$C R$} & \multirow{2}{*}{ Index } & \multicolumn{8}{|c|}{ Algorithms } \\
\hline & & DEPSO1 & DEPSO2 & DEPSO3 & DEPSO4 & IDEPSO1 & IDEPSO3 & IDEPSO4 & HSLSO \\
\hline \multirow{3}{*}{0.3} & Best & 10605.0819 & 10604.6741 & 10604.6852 & 10607.4662 & 10606.1858 & 10605.0052 & 10604.6783 & 10604.6741 \\
\hline & Mean & 10605.1859 & 10604.6741 & 10605.149 & 10612.4492 & 10611.6158 & 10605.5726 & 10604.7053 & 10604.67415 \\
\hline & Std & 0.0897 & 0.0 & 0.4871 & 2.6937 & 6.1401 & 0.5312 & 0.0235 & $9.4868 \mathrm{e}-015$ \\
\hline \multirow{3}{*}{0.5} & Best & 10604.6772 & 10604.6741 & 10604.6962 & 10611.6001 & 10604.6741 & 10604.9085 & 10604.7322 & 10604.6741 \\
\hline & Mean & 10604.6799 & 10604.6741 & 10605.196 & 10614.0376 & 10604.7516 & 10605.9641 & 10604.8006 & 10604.6741 \\
\hline & Std & 0.0028 & 0.0 & 0.7776 & 1.5733 & 0.2565 & 0.8166 & 0.06 & 0.0 \\
\hline \multirow{3}{*}{0.7} & Best & 10604.6741 & 10604.6741 & 10604.7015 & 10612.337 & 10604.6741 & 10605.3276 & 10604.7149 & 10604.6741 \\
\hline & Mean & 10604.6741 & 10604.6746 & 10606.5715 & 10617.2091 & 10604.6741 & 10606.0265 & 10604.7741 & 10604.6741 \\
\hline & Std & 0.0 & $3.6194 \mathrm{e}-016$ & 2.3115 & 4.0643 & 0.0 & 0.5369 & 0.0503 & 0.0 \\
\hline
\end{tabular}

360

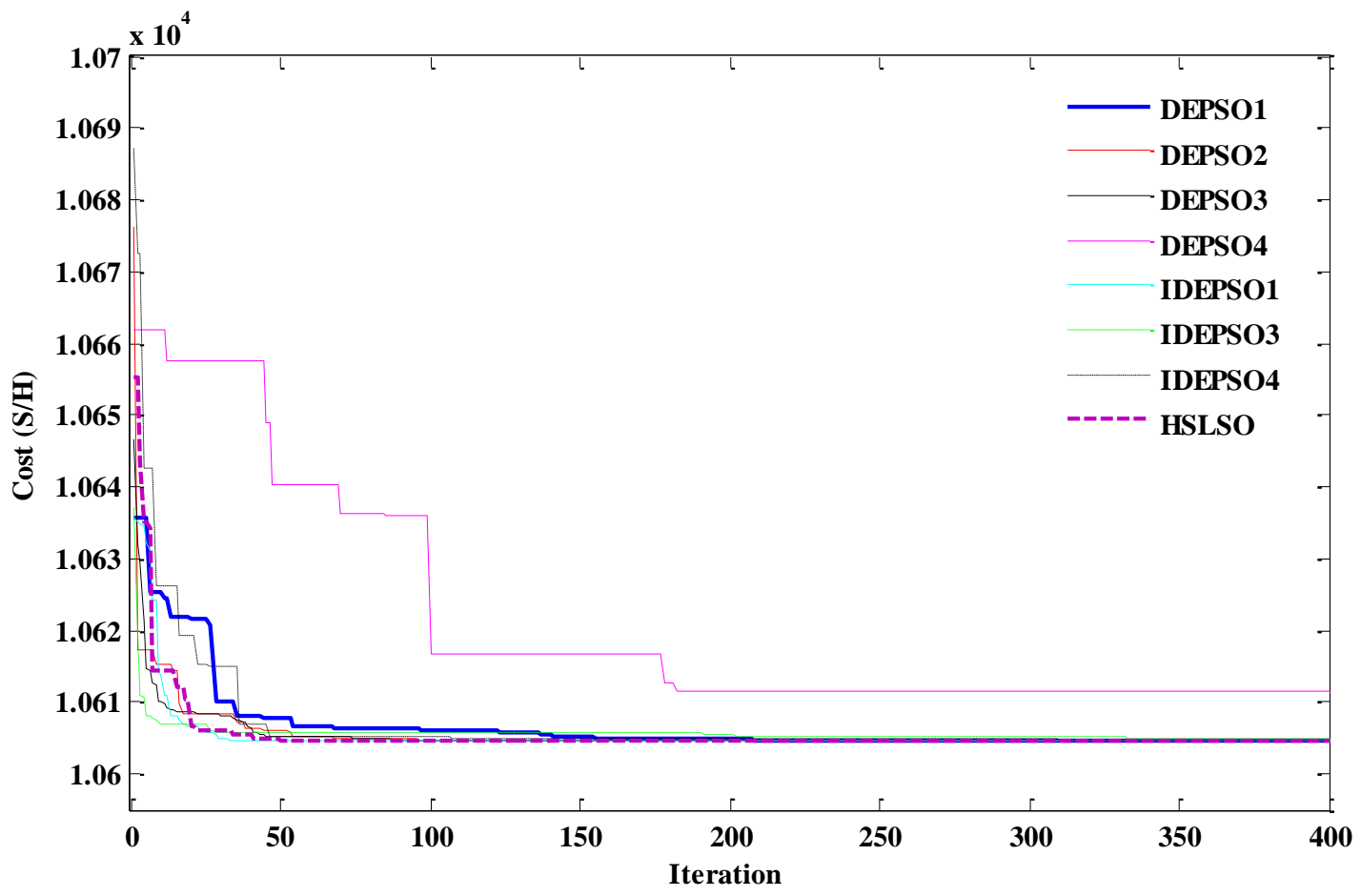

361

362

Fig. 2. Convergence characteristics of algorithms for test system 1. 
The best solutions obtained from HSLSO algorithm has been compared with direct search method (DSM) [54], Hopfield neural network (HNN) approach [61], covariance matrix adapted evolution strategy (CMAES) [40], and PSO with time-varying acceleration coefficients

367 (PSO_TVAC) [50]. Their best solutions are shown in Table 5. Ref. [40] reported a cost of $36810,574.0(\$ / H)$ for CMAES method but the reported results are infeasible as they do not satisfy 369 the area power balance constraints [50]. The performance of HSLSO and DEPSO algorithms are 370 very good among all algorithms for finding the optimal solution of MAED problem in the small371 scale system.

Table 5. Comparison of the simulation results for test system 1.

\begin{tabular}{|c|c|c|c|c|c|c|c|}
\hline Method & $P_{1}(\mathrm{MW})$ & $P_{2}(\mathrm{MW})$ & $P_{3}(\mathrm{MW})$ & $P_{4}(\mathrm{MW})$ & $T_{12}(\mathrm{MW})$ & $\sum P_{g}$ & Cost $(\$ / \mathrm{H})$ \\
\hline HNN [61] & - & - & - & - & - & - & 10605.0 \\
\hline DSM [54] & - & - & - & - & - & - & 10605.0 \\
\hline PSO_TVAC [50] $^{4}$ & 444.8047 & 139.1953 & 211.0609 & 324.9391 & -200.0000 & 1120.0 & 10604.6781 \\
\hline CMAES [40] $^{*}$ & 560.9383 & 168.9300 & 99.9890 & 290.1427 & -194.39 & 1120.0 & 10574.0 \\
\hline HSLSO & 445.1254 & 138.8747 & 211.9889 & 324.011 & -199.9999 & 1120.0 & 10604.6741 \\
\hline
\end{tabular}

375

For solving reserve constrained MAED (RCMAED) problem of test system 1, the area 377 reserves are taken as $40 \%$ of area 1 load demand (313.6 MW) for area 1 and 30\% of area 2 load 378 demand (100.8 MW) for area 2, and the tie-line limit is assumed to be $300 \mathrm{MW}$ [50]. The 379 obtained simulation results for RCMAED problem with optimal control variables using DEPSO 380 hybrid algorithms are given in Table 6 with the obtained best CR of Table 4 and $N_{P}=50$. The 381 convergence characteristics of the objective function (optimal total fuel cost) of all hybrid 382 algorithms are shown in Fig. 3, which is clear that most of the proposed DEPSO hybrid 383 algorithms can converge to their optimal total fuel cost in less iterations. 
385 Table 6. Comparison of the simulation results for reserve constrained MAED (RCMAED) problem of test 386 system 1.

\begin{tabular}{|c|c|c|c|c|c|c|c|c|}
\hline & \multicolumn{9}{|c|}{ Algorithms } \\
\cline { 2 - 9 } & DEPSO1 & DEPSO2 & DEPSO3 & DEPSO4 & IDEPSO1 & IDEPSO3 & IDEPSO4 & HSLSO \\
\hline$P_{1}(\mathrm{MW})$ & 369.5737 & 369.5737 & 369.6679 & 370.6286 & 369.5737 & 369.5965 & 369.5737 & 369.5737 \\
\hline$P_{2}(\mathrm{MW})$ & 114.4264 & 114.4264 & 114.5224 & 113.4921 & 114.4264 & 114.5100 & 114.4264 & 114.4264 \\
\hline$P_{3}(\mathrm{MW})$ & 295.9999 & 295.9999 & 295.8099 & 295.8795 & 295.9999 & 295.8939 & 295.9999 & 295.9999 \\
\hline$P_{4}(\mathrm{MW})$ & 340.0000 & 340.0000 & 340.0000 & 340.0000 & 340.0000 & 340.0000 & 340.0000 & 340.0000 \\
\hline$T_{12}(\mathrm{MW})$ & -299.9999 & -299.9999 & -299.8097 & -299.8793 & -299.9999 & -299.8935 & -299.9999 & -299.9999 \\
\hline $\begin{array}{c}\text { Reserve } \\
\text { area 1 }\end{array}$ & 315.9999 & 315.9999 & 315.8097 & 315.8793 & 315.9999 & 315.8935 & 315.9999 & 315.9999 \\
\hline $\begin{array}{c}\text { Reserve } \\
\text { area 2 }\end{array}$ & 104.0001 & 104.0001 & 104.1901 & 104.1205 & 104.0001 & 104.1061 & 104.0001 & 104.0001 \\
\hline $\begin{array}{c}\text { Best Cost } \\
(\$ / \mathrm{H})\end{array}$ & 10566.9946 & 10566.9946 & 10567.0107 & 10567.0114 & 10566.9946 & 10567.0062 & 10566.9946 & 10566.9946 \\
\hline $\begin{array}{c}\text { Mean Cost } \\
(\$ / \mathrm{H})\end{array}$ & 10566.9958 & 10566.9946 & 10571.0405 & 10567.0381 & 10566.9946 & 10567.2167 & 10566.9946 & 10566.9946 \\
\hline S.D. & 0.0164 & 0.0 & 2.0184 & 0.0358 & 0.0 & 0.1841 & 0.0 & 0.0 \\
\hline
\end{tabular}

387

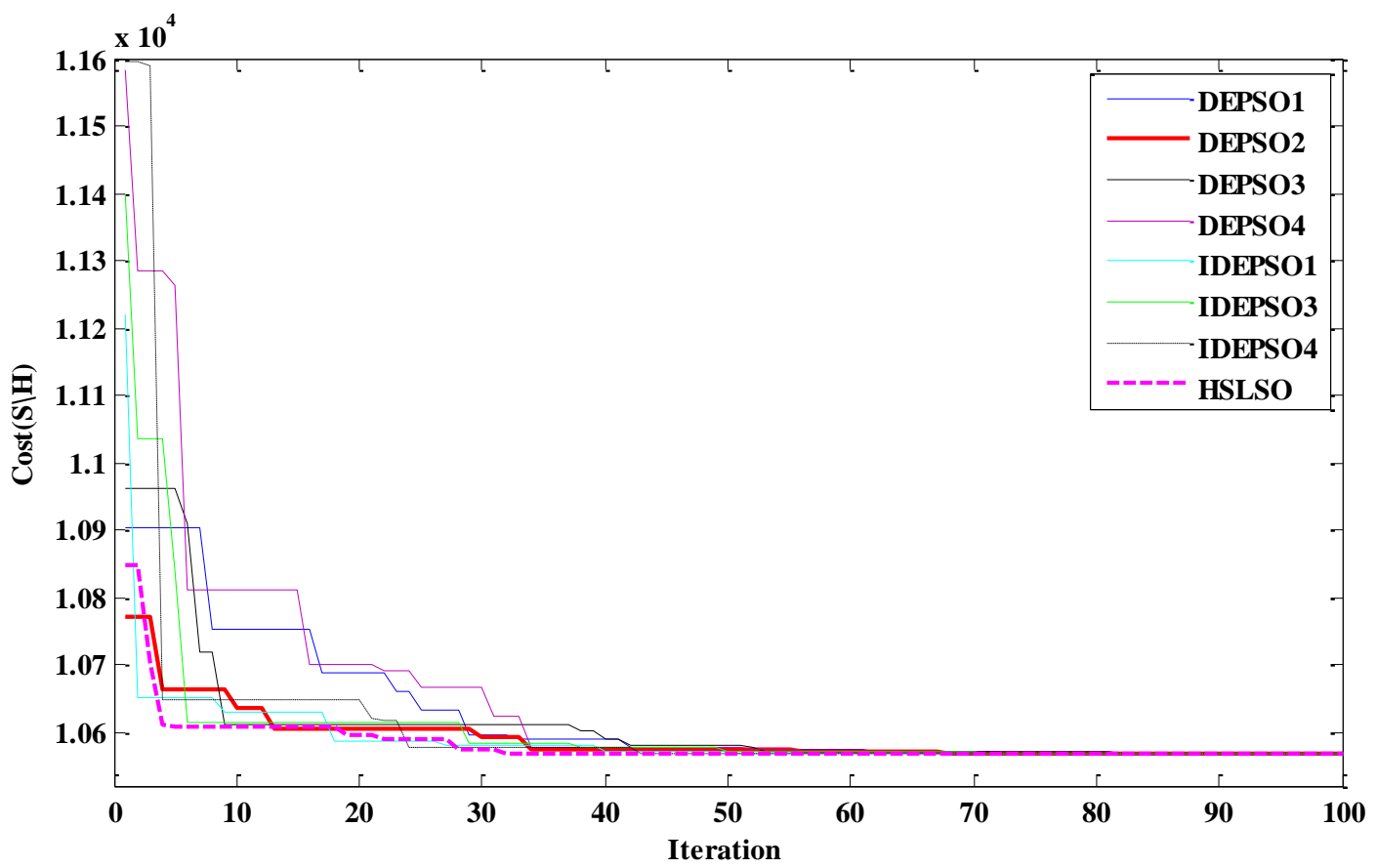

Fig. 3. Convergence characteristics of algorithms for reserve constrained MAED (RCMAED)

problem of test system 1 . 


\subsubsection{Case 1: Test system 2 for MAED problem based References [59, 62]}

394 This test system is a medium-scale test system with sixteen generating units, whose parameters with active tie-line flow limit are available in Ref. [59, 62]. The active load demand are set to $400 \mathrm{MW}$ for area $1\left(P_{1}, P_{2}, P_{3}\right.$ and $P_{4}$ units), $200 \mathrm{MW}$ for area $2\left(P_{5}, P_{6}, P_{7}\right.$ and $P_{8}$ units), 350

397 MW for area $3\left(P_{9}, P_{10}, P_{11}\right.$ and $P_{12}$ units $)$, and $300 \mathrm{MW}$ for area $4\left(P_{13}, P_{14}, P_{15}\right.$ and $P_{16}$ units).

398 The obtained results of DEPSO algorithms for the test system 2 with three different crossover

399 rates are tabulated in Table 7. The simulation results show that the proposed HSLSO algorithm

400 finds the best solution with minimum standard deviation for 30 trials, and the proposed improved

401 DEPSO algorithms yield better results than DEPSO algorithms in this test system. Convergence

402 characteristics of the various algorithms on test system 2 for the best solution of $C R=0.5$ are

403 plotted in Fig. 4. It is observed that the convergence characteristics for various DEPSO

404 algorithms are stable and steady.

405

Table 7. Comparison of the simulation results for test system 2 with different crossover rates.

\begin{tabular}{|c|c|c|c|c|c|c|c|c|c|}
\hline \multirow{2}{*}{$C R$} & \multirow{2}{*}{ Index } & \multicolumn{9}{|c|}{ Algorithms } \\
\cline { 3 - 9 } & & DEPSO1 & DEPSO2 & DEPSO3 & DEPSO4 & IDEPSO1 & IDEPSO3 & IDEPSO4 & HSLSO \\
\hline \multirow{3}{*}{0.3} & Best & 7584.5 & 7338.0787 & 7393.1215 & 7765.4585 & 7448.365 & 7362.5005 & 7338.2339 & 7338.1303 \\
\cline { 2 - 10 } & Mean & 7708.75 & 7342.6777 & 7430.6659 & 7905.9843 & 8269.4694 & 7419.1895 & 7339.9968 & 7338.4278 \\
\cline { 2 - 10 } & Std & 129.7749 & 8.9864 & 50.1082 & 125.8137 & 436.9393 & 58.9327 & 1.7621 & 0.4008 \\
\hline \multirow{3}{*}{0.5} & Best & 7371.4803 & 7338.6095 & 7344.7284 & 7915.3542 & 7338.0299 & 7368.2032 & 7342.3242 & 7337.042 \\
\cline { 2 - 10 } & Mean & 7599.7476 & 7340.0318 & 7411.8184 & 8173.1453 & 7339.7626 & 7419.9534 & 7350.7301 & 7337.8804 \\
\cline { 2 - 10 } & Std & 162.6943 & 1.6176 & 67.0561 & 158.8003 & 1.3896 & 43.1228 & 7.9251 & 0.6599 \\
\hline \multirow{3}{*}{0.7} & Best & 7375.1265 & 7338.0188 & 7379.8855 & 7916.0613 & 7338.0299 & 7507.8628 & 7341.1164 & $\mathbf{7 3 3 7 . 0 2 4}$ \\
\cline { 2 - 10 } & Mean & 7514.1761 & 7338.3982 & 7443.9999 & 7993.9544 & 7339.906 & 7755.9244 & 7349.2803 & 7338.5734 \\
\cline { 2 - 10 } & Std & 116.3733 & 0.4125 & 40.9244 & 66.0229 & 1.3896 & 295.8965 & 11.1432 & 0.7518 \\
\hline
\end{tabular}

407 


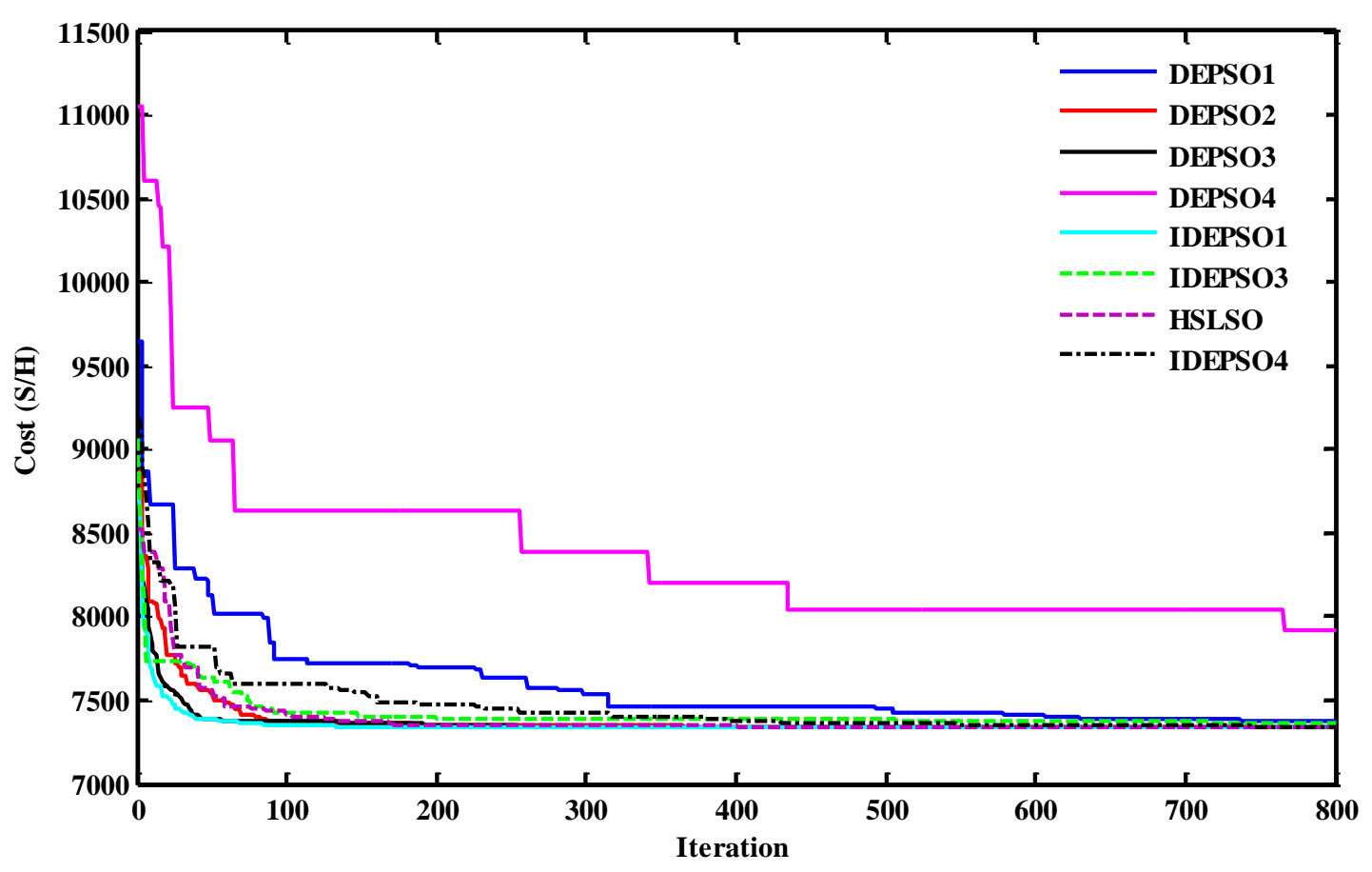
evolutionary programming (CEP) approach $\left(\sum P_{g}=1247.995 \mathrm{MW}\right)$ [56], network flow 416 programming (NFP) $\left(\sum P_{g}=1249.98 \mathrm{MW}\right)[62]$, and the hybrid harmony search (HHS) method $\left(\sum P_{g}=1249.29 \mathrm{MW}\right)[59]$

Fig. 4. Convergence characteristics of algorithms for test system 2.

The best solutions obtained by the hybrid algorithms and the solutions reported in literature are given in Table 8. The solution obtained by the HSLSO algorithm is a feasible solution $\left(\sum P_{g}=1250.0 \mathrm{MW}\right)$ compared with results reported in literature by methods such as the pattern search (PS) method $\left(\sum P_{g}=1249.9982 \mathrm{MW}\right)$ [52], PSO ( $\left.\sum P_{g}=1249.95 \mathrm{MW}\right)$, classical

$$
\left.\sum P_{0}=1249.29 \mathrm{MW}\right)[59]
$$

Table 8. Comparison of the simulation results for test system 2. 


\begin{tabular}{|c|c|c|c|c|c|c|c|}
\hline Area no. $(P D)$ & & PSO [56] & NFP [62] & CEP [56] & PS [52] & HHS [59] & HSLSO \\
\hline \multirow{4}{*}{$1(400 \mathrm{MW})$} & $P_{1}(\mathrm{MW})$ & 150.00 & 150.00 & 150.00 & 150.0000 & 150.00 & 150 \\
\hline & $P_{2}(\mathrm{MW})$ & 100.00 & 100.00 & 100.00 & 100.0000 & 100.00 & 100.0 \\
\hline & $P_{3}(\mathrm{MW})$ & 67.366 & 66.97 & 68.826 & 66.9710 & 66.86 & 67.3848 \\
\hline & $P_{4}(\mathrm{MW})$ & 100.00 & 100.00 & 99.985 & 100.0000 & 100.0 & 100.0 \\
\hline \multirow{4}{*}{$2(200 \mathrm{MW})$} & $P_{5}(\mathrm{MW})$ & 56.613 & 56.970 & 56.373 & 56.9718 & 57.04 & 57.0625 \\
\hline & $P_{6}(\mathrm{MW})$ & 95.474 & 96.250 & 93.519 & 96.2518 & 96.22 & 96.1749 \\
\hline & $P_{7}(\mathrm{MW})$ & 41.617 & 41.870 & 42.546 & 41.8718 & 41.74 & 41.8472 \\
\hline & $P_{8}(\mathrm{MW})$ & 72.356 & 72.520 & 72.647 & 72.5218 & 72.5 & 72.4505 \\
\hline \multirow{4}{*}{$3(350 \mathrm{MW})$} & $P_{9}(\mathrm{MW})$ & 50.00 & 50.00 & 50.00 & 50.0020 & 50.0 & 50.0 \\
\hline & $P_{10}(\mathrm{MW})$ & 35.973 & 36.270 & 36.399 & 36.2720 & 36.24 & 36.3190 \\
\hline & $P_{11}(\mathrm{MW})$ & 38.21 & 38.490 & 38.323 & 38.4920 & 38.39 & 38.5911 \\
\hline & $P_{12}(\mathrm{MW})$ & 37.162 & 37.320 & 36.903 & 37.3220 & 37.2 & 37.3719 \\
\hline \multirow{4}{*}{$4(300 \mathrm{MW})$} & $P_{13}(\mathrm{MW})$ & 150.000 & 150.000 & 150.0 & 150.0000 & 150.0 & 150.0 \\
\hline & $P_{14}(\mathrm{MW})$ & 100.000 & 100.000 & 100.0 & 100.0000 & 100.0 & 100.0 \\
\hline & $P_{15}(\mathrm{MW})$ & 57.830 & 57.050 & 56.648 & 57.0510 & 56.9 & 56.9272 \\
\hline & $P_{16}(\mathrm{MW})$ & 97.349 & 96.270 & 95.826 & 96.2710 & 96.2 & 95.8709 \\
\hline \multirow{6}{*}{$\begin{array}{l}\text { Active tie-line } \\
\text { power }\end{array}$} & $T_{12}(\mathrm{MW})$ & 0.00 & 0.00 & -0.018 & 0.0 & 0.0 & 0.0 \\
\hline & $T_{13}(\mathrm{MW})$ & 22.588 & 18.18 & 19.587 & 18.181 & 16.86 & 17.4643 \\
\hline & $T_{14}(\mathrm{MW})$ & -5.176 & -1.21 & $\begin{array}{l}-0.758 \\
\end{array}$ & -1.210 & 0.0 & -0.0795 \\
\hline & $T_{23}(\mathrm{MW})$ & 66.064 & 69.73 & 68.861 & 69.73 & 7061 & 70.2537 \\
\hline & $T_{24}(\mathrm{MW})$ & -0.004 & -2.11 & -1.789 & -2.111 & -3.11 & -2.7186 \\
\hline & $T_{34}(\mathrm{MW})$ & -100.000 & -100.0 & -99.927 & -100.0 & -100.0 & -100 \\
\hline \multicolumn{2}{|c|}{$\sum P_{g}$} & 1249.95 & 1249.98 & 1247.995 & 1249.9982 & 1249.29 & 1250.0 \\
\hline \multicolumn{2}{|c|}{ Cost $(\$ / H)$} & 7336.93 & 7337.00 & 7337.75 & 7336.98 & 7329.85 & 7337.0299 \\
\hline
\end{tabular}

421

\subsubsection{Case 2: Test system 2 for RCMAED and RCMAEED problems with reserve sharing}

\section{based on Reference [53]}

The different fuel and emission characteristics data of all generators, including all generators operating limits and tie-line limits, are available in Ref. [53]. The active load demand are set to $30 \mathrm{MW}$ for area $1\left(P_{1}, P_{2}, P_{3}\right.$ and $P_{4}$ units $), 50 \mathrm{MW}$ for area $2\left(P_{5}, P_{6}, P_{7}\right.$ and $P_{8}$ units), $40 \mathrm{MW}$ for area $3\left(P_{9}, P_{10}, P_{11}\right.$ and $P_{12}$ units $)$, and $60 \mathrm{MW}$ for area 4 ( $P_{13}, P_{14}, P_{15}$ and $P_{16}$ units). The spinning reserve requirement for the four areas are $30 \%$ of the area load demand in each area, i.e. 9 MW for area 1, $15 \mathrm{MW}$ for area 2,12MW for area 3 and 18MW for area 4, respectively. Tables 9 and 10 illustrate the optimal control variables characteristic for the fuel cost and emissions (Table.10) obtained using hybrid DEPSO algorithms for two RCMAED and RCMAEED problems with the obtained best CR of Table 7, respectively. The weighting factor is selected to be 120.0 for RCMAEED problem, and zero value for RCMAED problem. According to the presented results, the HSLSO algorithm has better performance than other hybrid DEPSO algorithms for RCMAED and RCMAEED problems.

Table 9. Comparison of the simulation results for RCMAED problem of test system 2. 


\begin{tabular}{|c|c|c|c|c|c|c|c|c|}
\hline \multirow{2}{*}{ (MW) } & \multicolumn{8}{|c|}{ Algorithms } \\
\hline & DEPSO1 & DEPSO2 & DEPSO3 & DEPSO4 & IDEPSO1 & IDEPSO3 & IDEPSO4 & HSLSO \\
\hline$P_{1}(\mathrm{MW})$ & 5.4643 & 3.1018 & 12.6855 & 12.6142 & $\begin{array}{l}13.5198 \\
\end{array}$ & 9.6169 & 0.4724 & 11.0552 \\
\hline$P_{2}(\mathrm{MW})$ & 0.3177 & 7.9364 & 8.9795 & 9.9933 & 8.5906 & 3.5813 & 7.5553 & 9.8604 \\
\hline$P_{3}(\mathrm{MW})$ & 12.9730 & 10.3067 & 7.5249 & 0.1144 & 6.6234 & 4.9329 & 10.0875 & 5.4901 \\
\hline$P_{4}(\mathrm{MW})$ & 11.1998 & 8.6684 & 0.7768 & 7.4458 & 1.3766 & 12.0000 & 11.9217 & 3.5849 \\
\hline$P_{5}(\mathrm{MW})$ & 11.9464 & 13.7007 & 18.3076 & 24.9810 & 23.9531 & 17.5893 & 1.1237 & 2.8162 \\
\hline$P_{6}(\mathrm{MW})$ & 9.7301 & 1.7089 & 5.9683 & 1.4095 & 3.4317 & 11.9977 & 11.9819 & 8.6228 \\
\hline$P_{7}(\mathrm{MW})$ & 12.0407 & 18.8862 & 17.8618 & 18.8194 & 16.5694 & 19.7774 & 19.9529 & 2.0908 \\
\hline$P_{8}(\mathrm{MW})$ & 16.2852 & 15.7602 & 7.8177 & 4.7207 & 6.0516 & 0.6361 & 16.9628 & 6.4706 \\
\hline$P_{9}(\mathrm{MW})$ & 0.2927 & 8.6018 & 21.5032 & 16.9843 & 12.7645 & 0.9991 & 0.4290 & 2.9635 \\
\hline$P_{10}(\mathrm{MW})$ & 13.3341 & 0.9835 & 3.1556 & 2.8846 & 9.9381 & 0.0777 & 1.0530 & 0.0500 \\
\hline$P_{11}(\mathrm{MW})$ & 0.1226 & 6.4470 & 4.1346 & 19.2703 & 3.1255 & 29.7699 & 9.2074 & 8.5821 \\
\hline$P_{12}(\mathrm{MW})$ & 26.2591 & 23.9569 & 11.2296 & 0.8976 & 14.1403 & 9.1460 & 29.3113 & 8.3853 \\
\hline$P_{13}(\mathrm{MW})$ & 0.0957 & 7.7491 & 10.3416 & 0.0538 & 1.1532 & 0.2214 & 10.6806 & 6.6636 \\
\hline$P_{14}(\mathrm{MW})$ & 19.7606 & 0.3072 & 19.3828 & 10.5401 & 8.0550 & 0.3289 & 18.8727 & 3.3023 \\
\hline$P_{15}(\mathrm{MW})$ & 29.3035 & 29.8405 & 1.3674 & 28.1829 & 26.5102 & 29.3861 & 25.0099 & 2.4392 \\
\hline$P_{16}(\mathrm{MW})$ & 10.8821 & 22.0311 & 28.9625 & 21.1077 & 24.2042 & 29.9163 & 5.3876 & 7.6249 \\
\hline$T_{12}(\mathrm{MW})$ & -0.0197 & -0.0416 & 0.0121 & 0.0434 & 0.0212 & -0.0100 & 0.0235 & 0.0273 \\
\hline$T_{13}(\mathrm{MW})$ & 0.0115 & 0.0121 & -0.0114 & -0.0226 & 0.0276 & $\begin{array}{l}-0.0009 \\
\end{array}$ & -0.0139 & -0.0092 \\
\hline$T_{14}(\mathrm{MW})$ & -0.0419 & 0.0529 & -0.0346 & 0.1426 & 0.0616 & 0.1436 & 0.0341 & \begin{tabular}{|l|l|}
-0.0271 \\
\end{tabular} \\
\hline$T_{23}(\mathrm{MW})$ & -0.0097 & -0.0041 & -0.0231 & -0.0085 & -0.0114 & $\begin{array}{l}-0.0038 \\
\end{array}$ & 0.0105 & -0.0037 \\
\hline$T_{24}(\mathrm{MW})$ & 0.0003 & 0.0185 & -0.0099 & -0.0245 & 0.0265 & -0.0049 & 0.0198 & 0.0145 \\
\hline$T_{34}(\mathrm{MW})$ & 0.0007 & -0.0019 & -0.0131 & -0.0012 & -0.0075 & 0.0020 & -0.0012 & -0.0057 \\
\hline $\mathrm{RC12}$ & -0.0317 & $\begin{array}{l}-0.0019 \\
\end{array}$ & 0.0492 & 0.0028 & -0.0054 & $\begin{array}{l}-0.0234 \\
\end{array}$ & -0.0082 & 0.0332 \\
\hline $\mathrm{RC} 13$ & 0.0105 & 0.0177 & 0.0228 & -0.0147 & 0.0122 & 0.0379 & -0.0079 & 0.0040 \\
\hline RC14 & 0.0768 & 0.0071 & -0.0081 & -0.0005 & 0.0085 & 0.0418 & -0.0413 & \begin{tabular}{|l|l|}
-0.0134 \\
\end{tabular} \\
\hline $\mathrm{RC} 23$ & $\begin{array}{l}-0.0221 \\
\end{array}$ & -0.0134 & -0.0009 & 0.0019 & 0.0164 & -0.0173 & -0.0042 & $\begin{array}{l}-0.0251 \\
\end{array}$ \\
\hline $\mathrm{RC} 24$ & 0.0254 & 0.0130 & 0.0304 & 0.0026 & 0.0091 & 0.0306 & 0.0329 & 0.0391 \\
\hline RC34 & 0.013 & 0.0076 & -0.0009 & -0.0041 & 0.0046 & 0.0020 & 0.0081 & 0.0049 \\
\hline \multicolumn{9}{|l|}{ Reserve area 1} \\
\hline \multicolumn{9}{|l|}{ Reserve area 2} \\
\hline \multirow{2}{*}{\multicolumn{9}{|c|}{ Reserve area 3}} \\
\hline Reserve area 4 & & & & & & & & \\
\hline Cost $(\$ \mathrm{~h})$ & 2189.2012 & 2183.6782 & 2186.6061 & 2190.5887 & 2178.2986 & 2186.3202 & 2182.2914 & 2159.8128 \\
\hline Mean & & & & & & & & \\
\hline S.D. & & & & & & & & \\
\hline
\end{tabular}

437 Table 10. Comparison of the simulation results for reserve constrained multi area

438 environmental/economic dispatch (RCMAEED) problem of test system 2.

\begin{tabular}{|c|c|c|c|c|c|c|c|c|}
\hline$(\mathrm{MW})$ & DEPSO1 & DEPSO2 & DEPSO3 & DEPSO4 & IDEPSO1 & IDEPSO3 & IDEPSO4 & HSLSO \\
\hline$P_{1}(\mathrm{MW})$ & 10.4136 & 12.6447 & 10.0196 & 4.9260 & 13.2116 & 12.2540 & 12.8502 & $\mathbf{1 3 . 6 0 0 4}$ \\
\hline$P_{2}(\mathrm{MW})$ & 4.9644 & 6.6592 & 5.1395 & 7.2540 & 6.6790 & 9.2143 & 7.5463 & $\mathbf{5 . 3 8 8 0}$ \\
\hline$P_{3}(\mathrm{MW})$ & 3.0067 & 0.1061 & 10.2519 & 10.2999 & 7.3117 & 4.0872 & 3.7010 & $\mathbf{5 . 1 2 1 8}$ \\
\hline$P_{4}(\mathrm{MW})$ & 11.5211 & 10.7641 & 4.5322 & 7.4911 & 2.7739 & 4.4428 & 5.9252 & $\mathbf{5 . 9 2 9 9}$ \\
\hline$P_{5}(\mathrm{MW})$ & 6.5876 & 16.3608 & 14.7624 & 19.5174 & 15.0576 & 24.8488 & 23.4908 & $\mathbf{2 2 . 6 1 0 9}$ \\
\hline$P_{6}(\mathrm{MW})$ & 9.7131 & 7.3302 & 11.7687 & 10.1479 & 4.7809 & 3.6403 & 0.6111 & $\mathbf{8 . 3 7 3 8}$ \\
\hline$P_{7}(\mathrm{MW})$ & 18.8575 & 13.6234 & 19.4621 & 4.9097 & 13.4996 & 10.4683 & 17.4849 & $\mathbf{8 . 6 5 2 4}$ \\
\hline$P_{8}(\mathrm{MW})$ & 14.9039 & 12.7100 & 4.0304 & 15.4238 & 16.6493 & 11.0494 & 8.4428 & $\mathbf{1 0 . 3 4 3 7}$ \\
\hline$P_{9}(\mathrm{MW})$ & 23.9743 & 12.1719 & 22.6546 & 28.6957 & 11.6720 & 13.0985 & 14.7230 & $\mathbf{1 2 . 2 8 5 7}$ \\
\hline$P_{10}(\mathrm{MW})$ & 6.3174 & 6.1967 & 3.8454 & 5.5386 & 10.1620 & 15.1976 & 6.2322 & $\mathbf{8 . 7 8 2 0}$ \\
\hline$P_{11}(\mathrm{MW})$ & 0.5079 & 10.4179 & 3.2815 & 2.0624 & 3.9674 & 2.6575 & 5.2089 & $\mathbf{7 . 8 8 8 2}$ \\
\hline$P_{12}(\mathrm{MW})$ & 9.1893 & 11.2001 & 10.2180 & 3.7338 & 14.2051 & 9.0514 & 13.7952 & $\mathbf{1 1 . 0 3 5 2}$ \\
\hline$P_{13}(\mathrm{MW})$ & 10.9743 & 7.7329 & 9.6932 & 9.9038 & 8.9539 & 10.7064 & 10.7395 & $\mathbf{1 0 . 9 6 2 8}$ \\
\hline$P_{14}(\mathrm{MW})$ & 16.1252 & 9.9463 & 19.5799 & 16.1223 & 19.9808 & 15.3404 & 16.7964 & $\mathbf{1 6 . 2 9 8 0}$ \\
\hline
\end{tabular}




\begin{tabular}{|c|c|c|c|c|c|c|c|c|}
\hline$P_{15}(\mathrm{MW})$ & 14.3829 & 15.8206 & 22.4566 & 14.6359 & 12.7618 & 11.0278 & 13.1715 & $\mathbf{1 3 . 3 9 6 4}$ \\
\hline$P_{16}(\mathrm{MW})$ & 18.5557 & 26.3090 & 8.3138 & 19.4639 & 18.3250 & 22.9130 & 19.2884 & $\mathbf{1 9 . 3 2 4 0}$ \\
\hline$T_{12}(\mathrm{MW})$ & -0.0302 & -0.0209 & -0.0054 & 0.0394 & 0.0109 & -0.0312 & -0.0182 & $\mathbf{0 . 0 2 6 9}$ \\
\hline$T_{13}(\mathrm{MW})$ & -0.0005 & -0.0012 & -0.0023 & 0.0131 & 0.0048 & -0.0141 & 0.0233 & $\mathbf{- 0 . 0 0 4 1}$ \\
\hline$T_{14}(\mathrm{MW})$ & -0.0566 & 0.1936 & -0.0535 & -0.0856 & -0.0320 & 0.0344 & 0.0286 & $\mathbf{0 . 0 0 6 0}$ \\
\hline$T_{23}(\mathrm{MW})$ & 0.0005 & 0.0061 & 0.0142 & -0.0029 & -0.0057 & 0.0044 & 0.0085 & $\mathbf{0 . 0 0 4 1}$ \\
\hline$T_{24}(\mathrm{MW})$ & 0.0410 & -0.0074 & 0.0021 & 0.0056 & 0.0060 & -0.0200 & -0.0175 & $\mathbf{0 . 0 0 2 4}$ \\
\hline$T_{34}(\mathrm{MW})$ & -0.0141 & 0.0104 & 0.0125 & -0.0044 & -0.0009 & -0.0037 & -0.0131 & $\mathbf{0 . 0 0 6 8}$ \\
\hline RC12 & 0.0045 & 0.0151 & -0.0332 & 0.0177 & -0.0475 & 0.0272 & 0.0122 & $\mathbf{0 . 0 1 5 8}$ \\
\hline RC13 & -0.0159 & -0.0087 & 0.0125 & 0.0299 & 0.0167 & -0.0003 & -0.0006 & $\mathbf{- 0 . 0 0 0 8}$ \\
\hline RC14 & 0.0372 & 0.0040 & 0.0855 & -0.0706 & 0.0247 & -0.0410 & 0.0919 & $\mathbf{- 0 . 0 5 8 7}$ \\
\hline RC23 & 0.0233 & -0.0005 & 0.0056 & 0.0079 & 0.0234 & 0.0142 & 0.0080 & $\mathbf{- 0 . 0 0 1 5}$ \\
\hline RC24 & 0.0117 & 0.0118 & 0.0208 & -0.0072 & 0.0208 & 0.0314 & 0.0071 & $\mathbf{0 . 0 2 5 3}$ \\
\hline RC34 & 0.0001 & 0.0026 & 0.0031 & 0.0040 & 0.0021 & -0.0021 & -0.0031 & $\mathbf{- 0 . 0 0 0 2}$ \\
\hline Reserve area 1 & & & & & & & \\
\hline Reserve area 2 & & & & & & & \\
\hline Reserve area 3 & & & & & & & \\
\hline Reserve area 4 & & & & & & \\
\hline Cost (\$h) & 2194.6627 & 2182.579 & 2190.9533 & 2202.7789 & 2186.0603 & 2185.0514 & 2183.0054 & $\mathbf{2 1 8 2 . 5 7 5}$ \\
\hline Emission (ton/h) & 4.0435 & 3.5833 & 4.465 & 4.3742 & 3.3776 & 3.5941 & 3.6018 & $\mathbf{3 . 2 6 0 5}$ \\
\hline
\end{tabular}

\subsection{Test system 3: A two-area system with forty generating units}

441 The test system 3 is a large-scale power system which has generating units with POZ, VPL

442 effects, and ramp rate limits $[50,64]$. The units $P_{1}$ to $P_{20}$ are assumed to be in area one and units

$443 \quad P_{21}$ to $P_{40}$ are in area two. The total load is $10,500 \mathrm{MW}$ in which $7500 \mathrm{MW}$ is set as the active

444 load demand for area 1 and $3000 \mathrm{MW}$ is set as the active load demand for area 2 , and the

445 maximum transmission capacity limit between two areas is $1500 \mathrm{MW}$. The results of the

446 proposed algorithms for the test system 3 with the crossover rate $C R=0.5$ are tabulated in Table

447 11. The obtained results show that the HSLSO finds the best solution in comparison with other

448 algorithms for the large-scale system, and the proposed improved DEPSO algorithms yield better

449 results than DEPSO algorithms, in this test system. The convergence characteristics for the

450 proposed DEPSO algorithms are shown in Fig. 5. It is observed that the convergence

451 characteristic of the total fuel cost of generating units obtained by the HSLSO is slightly better

452 than that of the other DEPSO algorithms. Table 12 compares the best solution obtained using

453 HSLSO algorithm and DE algorithm with chaotic sequences based on logistic map (DEC2) [50, 
454 78]. The results show that HSLSO algorithm is successfully implemented to solve the large-scale

455 MAED problem with the generator constraints.

456

457 Table 11. Comparison of the simulation results for test system 3 with $C R=0.5$.

458

\begin{tabular}{|c|c|c|c|c|c|c|c|c|}
\hline \multirow{2}{*}{ Index } & \multicolumn{8}{|c|}{ Algorithms } \\
\hline & DEPSO1 & DEPSO2 & DEPSO3 & DEPSO4 & IDEPSO1 & IDEPSO3 & IDEPSO4 & HSLSO \\
\hline Best & 125299.5631 & 125179.5581 & 127386.3364 & 128641.7046 & 125594.007 & 127226.188 & 127457.4462 & 125100.2621 \\
\hline Mean & 125474.4525 & 125421.1636 & 128757.9549 & 128957.7981 & 126238.8349 & 127742.0182 & 127744.5247 & 125384.4464 \\
\hline Std & 173.9205 & 157.2532 & 860.0746 & 263.9482 & 478.2639 & 378.8191 & 247.7480 & 104.2493 \\
\hline
\end{tabular}

459

461

462

463

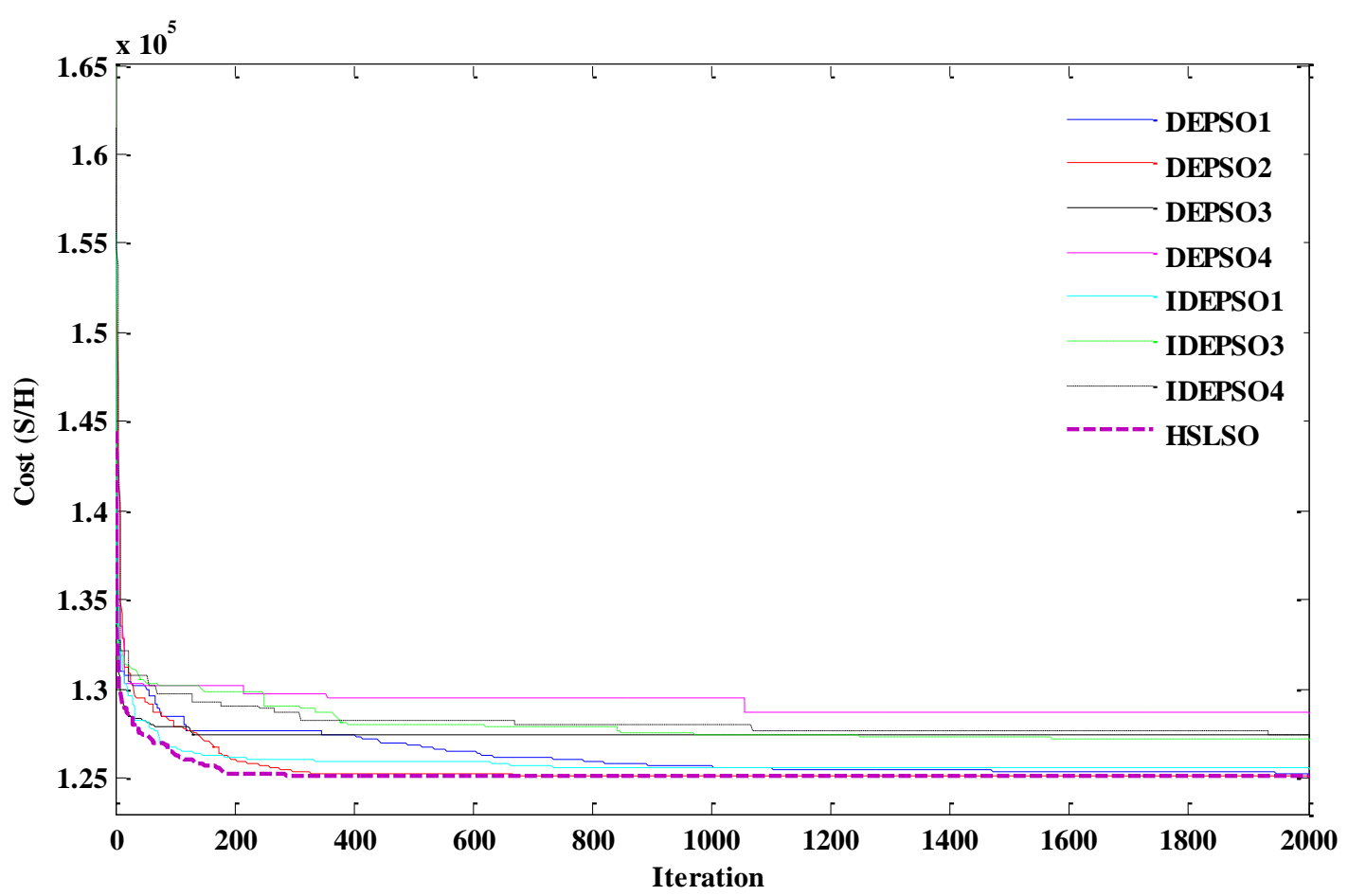

Fig. 5. Convergence characteristics of algorithms for test system 3.

Table 12. Comparison of the simulation results for test system 3.

\begin{tabular}{|c|c|c|c|c|c|c|c|}
\hline \multicolumn{4}{|c|}{ DEC2 $[50,78]$} & \multicolumn{4}{c|}{ HSLSO } \\
\hline \multicolumn{2}{|c|}{ Area 1 $(P D=7500 \mathrm{MW})$} & \multicolumn{2}{|c|}{ Area 2 $(P D=3000 \mathrm{MW})$} & \multicolumn{2}{c|}{ Area 1 $(P D=7500 \mathrm{MW})$} & \multicolumn{2}{c|}{ Area 2 $(P D=3000 \mathrm{MW})$} \\
\hline$P_{1}(\mathrm{MW})$ & 112.8292 & $P_{21}(\mathrm{MW})$ & 343.7598 & $P_{1}(\mathrm{MW})$ & 110.8012 & $P_{21}(\mathrm{MW})$ & 523.2792 \\
\hline$P_{2}(\mathrm{MW})$ & 114.0000 & $P_{22}(\mathrm{MW})$ & 433.5196 & $P_{2}(\mathrm{MW})$ & 113.9997 & $P_{22}(\mathrm{MW})$ & 523.2791 \\
\hline$P_{3}(\mathrm{MW})$ & 97.3999 & $P_{23}(\mathrm{MW})$ & 523.2794 & $P_{3}(\mathrm{MW})$ & 120.0 & $P_{23}(\mathrm{MW})$ & 523.2794 \\
\hline$P_{4}(\mathrm{MW})$ & 179.7331 & $P_{24}(\mathrm{MW})$ & 550.0000 & $P_{4}(\mathrm{MW})$ & 179.7331 & $P_{24}(\mathrm{MW})$ & 523.2794 \\
\hline$P_{5}(\mathrm{MW})$ & 97.0000 & $P_{25}(\mathrm{MW})$ & 550.0000 & $P_{5}(\mathrm{MW})$ & 95.551 & $P_{25}(\mathrm{MW})$ & 523.2795 \\
\hline$P_{6}(\mathrm{MW})$ & 68.0001 & $P_{26}(\mathrm{MW})$ & 254.0000 & $P_{6}(\mathrm{MW})$ & 140.0 & $P_{26}(\mathrm{MW})$ & 254.0 \\
\hline$P_{7}(\mathrm{MW})$ & 300.0 & $P_{27}(\mathrm{MW})$ & 10.0000 & $P_{7}(\mathrm{MW})$ & 300.0 & $P_{27}(\mathrm{MW})$ & 10.0001 \\
\hline
\end{tabular}




\begin{tabular}{|c|c|c|c|c|c|c|c|}
\hline$P_{8}(\mathrm{MW})$ & 284.5997 & $P_{28}(\mathrm{MW})$ & 10.0001 & $P_{8}(\mathrm{MW})$ & 284.5997 & $P_{28}(\mathrm{MW})$ & 10.0 \\
\hline$P_{9}(\mathrm{MW})$ & 284.5997 & $P_{29}(\mathrm{MW})$ & 10.0000 & $P_{9}(\mathrm{MW})$ & 284.5997 & $P_{29}(\mathrm{MW})$ & 10.0 \\
\hline$P_{10}(\mathrm{MW})$ & 130.0 & $P_{30}(\mathrm{MW})$ & 47.0000 & $P_{10}(\mathrm{MW})$ & 270.0 & $P_{30}(\mathrm{MW})$ & 87.7997 \\
\hline$P_{11}(\mathrm{MW})$ & 360.0 & $P_{31}(\mathrm{MW})$ & 159.7331 & $P_{11}(\mathrm{MW})$ & 94.0 & $P_{31}(\mathrm{MW})$ & 188.5959 \\
\hline$P_{12}(\mathrm{MW})$ & 94.0001 & $P_{32}(\mathrm{MW})$ & 190.0000 & $P_{12}(\mathrm{MW})$ & 300.0 & $P_{32}(\mathrm{MW})$ & 159.7331 \\
\hline$P_{13}(\mathrm{MW})$ & 304.5196 & $P_{33}(\mathrm{MW})$ & 163.7269 & $P_{13}(\mathrm{MW})$ & 304.5195 & $P_{33}(\mathrm{MW})$ & 159.733 \\
\hline$P_{14}(\mathrm{MW})$ & 500.0 & $P_{34}(\mathrm{MW})$ & 164.7998 & $P_{14}(\mathrm{MW})$ & 394.2797 & $P_{34}(\mathrm{MW})$ & 164.8002 \\
\hline$P_{15}(\mathrm{MW})$ & 484.0392 & $P_{35}(\mathrm{MW})$ & 200.0000 & $P_{15}(\mathrm{MW})$ & 484.0395 & $P_{35}(\mathrm{MW})$ & 164.7998 \\
\hline$P_{16}(\mathrm{MW})$ & 500.0 & $P_{36}(\mathrm{MW})$ & 164.7998 & $P_{16}(\mathrm{MW})$ & 484.0391 & $P_{36}(\mathrm{MW})$ & 164.7998 \\
\hline$P_{17}(\mathrm{MW})$ & 489.2794 & $P_{37}(\mathrm{MW})$ & 110.000 & $P_{17}(\mathrm{MW})$ & 489.2794 & $P_{37}(\mathrm{MW})$ & 89.1143 \\
\hline$P_{18}(\mathrm{MW})$ & 500.0 & $P_{38}(\mathrm{MW})$ & 57.0571 & $P_{18}(\mathrm{MW})$ & 489.2796 & $P_{38}(\mathrm{MW})$ & 89.114 \\
\hline$P_{19}(\mathrm{MW})$ & 550.0000 & $P_{39}(\mathrm{MW})$ & 25.0000 & $P_{19}(\mathrm{MW})$ & 549.9998 & $P_{39}(\mathrm{MW})$ & 89.1134 \\
\hline$P_{20}(\mathrm{MW})$ & 550.0000 & $P_{40}(\mathrm{MW})$ & 511.2794 & $P_{20}(\mathrm{MW})$ & 511.2791 & $P_{40}(\mathrm{MW})$ & 242.0001 \\
\hline$T_{12}(M W)$ & \multicolumn{3}{|c|}{-1500.0000} & $T_{12}(\mathrm{MW})$ & \multicolumn{3}{|c|}{-1500.0} \\
\hline$\sum P_{g}$ & \multicolumn{3}{|c|}{10500.0} & $\sum P_{g}$ & \multicolumn{3}{|c|}{10500.0001} \\
\hline Cost $(\$ / H)$ & \multicolumn{3}{|c|}{127344.8528} & Cost $(\$ / H)$ & \multicolumn{3}{|c|}{125100.2621} \\
\hline
\end{tabular}

464

\section{Conclusions}

In this paper, four IDEPSO techniques were proposed for solving optimal MAED, RCMAED, RCMAED with reserve sharing, and RCMAEED with reserve sharing problems. MAED problems are an extension of ELD problem in power systems, and multi-area systems considered in this study are a two-area system with four generating units, a four-area system with sixteen generating units, and a two-area system with forty generating units. The simulation results show that IDEPSO techniques, in particular HSLSO algorithm, have suitable performance in balancing the global search ability and convergence characteristics, and better performance in solution's quality than other algorithms proposed in the literature. So, it is believed that the proposed HSLSO algorithm in this study is capable of effectively and quickly solving optimization problems in power systems.

\section{Appendix: Comparison of HSLSO with standard PSO algorithms}

In this section, we consider two standard PSO (SPSO) algorithms in the recent literature, including SPSO2011 [79] and modified PSO (MPSO) [80-81], for comparison with HSLSO algorithm using standard benchmark test functions such as Rosenbrock $\left(f_{3}\right)$, Rastrigin $\left(f_{4}\right)$ and Ackley $\left(f_{6}\right)$ functions under same conditions and with their original control parameters in the literature. The obtained optimal results after 25 runs are given in Table 13, and also the convergence characteristics of these algorithms for 
482 Rastrigin function with $D=60$ are shown in Fig. 6. The HSLSO algorithm provides better optimal results

483 with faster convergence compared to SPSO2011 and MPSO.

484 Table 13. Comparison of the HSLSO and other algorithms for benchmark test functions.

\begin{tabular}{|c|c|c|c|c|c|c|c|c|c|c|}
\hline \multirow{2}{*}{ Function } & \multirow{2}{*}{$\mathrm{D}$} & \multicolumn{3}{|c|}{ MPSO } & \multicolumn{3}{|c|}{ SPSO2011 } & \multicolumn{3}{|c|}{ HSLSO } \\
\hline & & Best & Mean & Std & Best & Mean & Std & Best & Mean & Std \\
\hline \multirow{2}{*}{ Rosenbrock } & 30 & 20.7643 & 24.1874 & 13.9342 & 13.7951 & 13.8851 & 0.7157 & 12.4180 & 13.3847 & 1.0329 \\
\hline & 60 & 60.1641 & 71.6428 & 38.1262 & 48.2355 & 48.8663 & 1.0095 & 43.2785 & 44.5325 & 1.1041 \\
\hline \multirow{2}{*}{ Rastrigin } & 30 & 48.3716 & 53.2907 & 23.9066 & 34.5925 & 34.5249 & 3.2363 & 0.0 & 0.0 & 0.0 \\
\hline & 60 & 154.6357 & 282.8053 & 49.8403 & 138.0560 & 155.2106 & 11.3320 & 0.0 & 0.0 & 0.0 \\
\hline \multirow{2}{*}{ Ackley } & 30 & 1.479 & 11.5197 & 10.0050 & $\begin{array}{c}4.4409 \mathrm{e}- \\
015\end{array}$ & $\begin{array}{c}7.1054 \mathrm{e}- \\
015\end{array}$ & $\begin{array}{c}1.7763 \mathrm{e}- \\
015\end{array}$ & $\begin{array}{c}\text { 8.8818e- } \\
016\end{array}$ & $\begin{array}{c}\text { 8.8818e- } \\
016\end{array}$ & 0.0 \\
\hline & 60 & 1.5915 & 20.7934 & 18.0593 & $\begin{array}{c}\text { 7.9936e- } \\
015\end{array}$ & 0.8308 & 0.9788 & $\begin{array}{c}\text { 8.8818e- } \\
016\end{array}$ & $\begin{array}{c}\text { 8.8818e- } \\
016\end{array}$ & 0.0 \\
\hline
\end{tabular}

485

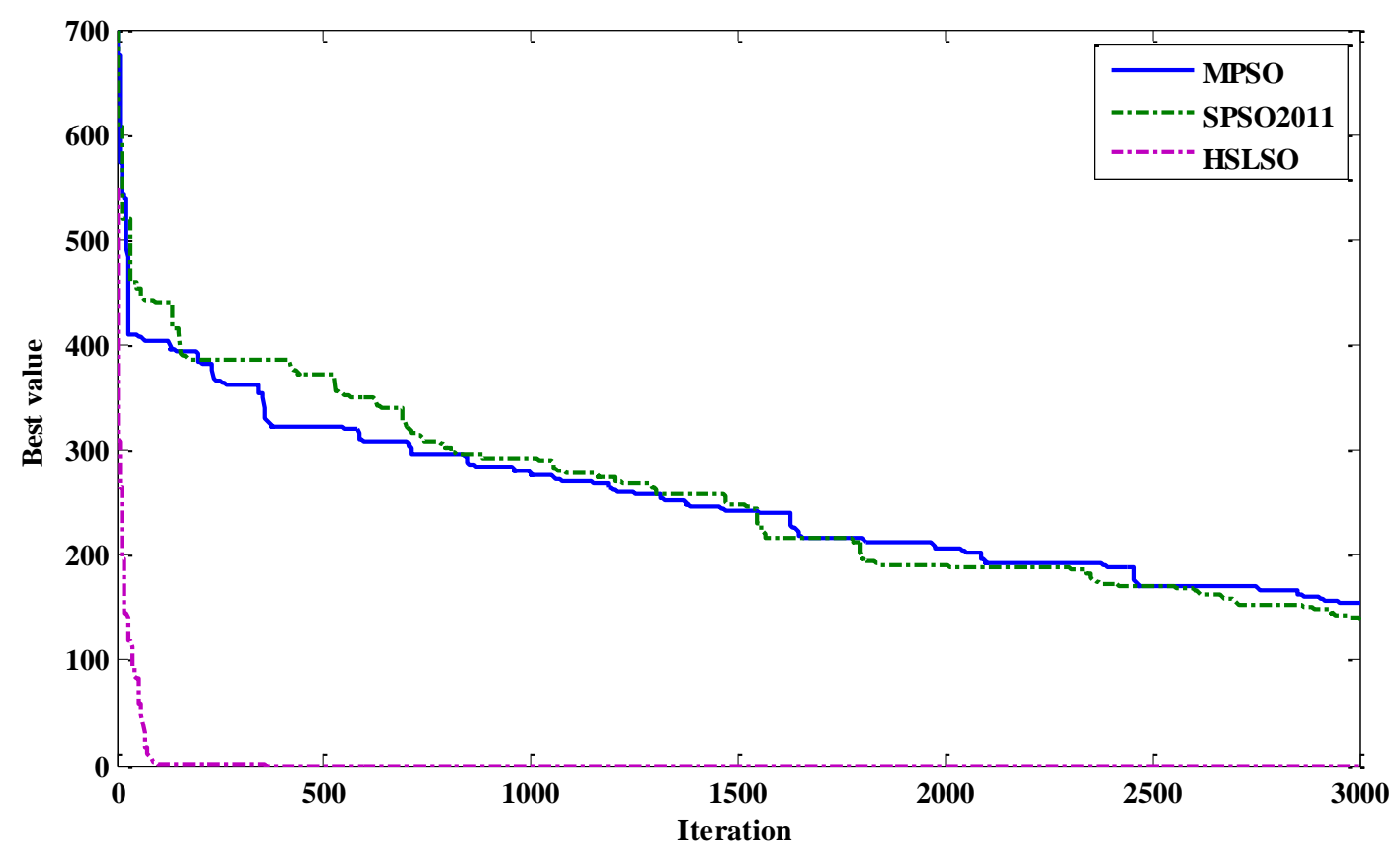

486

487

488

489

490

Fig. 6. Convergence characteristics of algorithms for Rastrigin function with $D=60$. 


\section{References}

492 [1] Park JH, Lee KY, Sode-Yome A. Adaptive hopfield neural networks for economic load dispatch. IEEE Trans Power Syst 1998; 13: 519-25.

494 [2] Liang Z-X, Glover JD. A zoom feature for a dynamic programming solution to economic dispatch including transmission losses. IEEE Trans Power Syst 1992; 7 (2): 544-50.

496 [3] Park JH, Kim YS, Eom IK, Lee KY. Economic load dispatch for piecewise quadratic cost 497 function using hopfield neural network. IEEE Trans Power Syst 1993; 8 (3): 1030-8.

[4] Jeddi B, Vahidinasab V. A modified harmony search method for environmental/economic load dispatch of real-world power systems. Energy Convers Manage 2014; 78: 661-75.

500 [5] Walters DC, Sheble GB. Genetic algorithm solution of economic dispatch with valve point 501 loading. IEEE Trans Power Syst 1993; 8 (3): 1325-32.

[6] Damousis IG, Bakirtzis AG, Dokopoulos PS. Network-constrained economic dispatch using real-coded genetic algorithm, IEEE Trans Power Syst 2003; 18 (1): 198-205.

[7] Gaing ZL. Particle swarm optimization to solving the economic dispatch considering the generator constraints. IEEE Trans Power Syst 2003; 18 (3): 1187-95.

[8] Vlachos AG, Biskas PN. Simultaneous clearing of energy and reserves in multi-area markets under mixed pricing rules. IEEE Trans Power Syst 2011; 26 (4): 2460-71. for solving economic dispatch problems. Inform Sci 2015; 295: 609-32. [10] Amjady N, Sharifzadeh H. Solution of non-convex economic dispatch problem considering valve loading effect by a new modified differential evolution algorithm. Int $\mathbf{J}$ Electr Power 512 Energy Syst 2010; 32 (8): 893-903.

513 [11] Basu M, Chowdhury A. Cuckoo search algorithm for economic dispatch. Energy 2013; 60: 514 99-108.

515 [12] Mohammadi-Ivatloo B, Rabiee A, Soroudi A, Ehsan M. Iteration \{PSO\} with time varying 516 acceleration coefficients for solving non-convex economic dispatch problems. Int J Electr Power 517 Energy Syst 201242 (1): 508-16.

518 [13] Sayah S, Hamouda A. A hybrid differential evolution algorithm based on particle swarm 519 optimization for nonconvex economic dispatch problems. Appl Soft Comput 2013, 13: 1608-19. 
[14] Aghaei J, Niknam T, Azizipanah-Abarghooee R, Arroyo José M. Scenario-based dynamic economic emission dispatch considering load and wind power uncertainties. Int J Electr Power Energy Syst 2013;47:351-67.

[15] Soroudi CA, Ehsan M. IGDT based robust decision making tool for DNOs in load procurement under severe uncertainty. IEEE Trans Smart Grid 2013; 4 (2):886-95

[16] Ivatloo BM, Zareipour H, Amjady N. Application of information gap decision theory to risk-constrained self-scheduling of GenCos. IEEE Trans Power Syst 2013; 28 (2): 1093-102. [17] Moradi-Dalvand M, Mohammadi-Ivatloo B, Najafi A, Rabiee A. Continuous quick group search optimizer for solving non-convex economic dispatch problems. Electr Power Syst Res 2012; 93: 93-105.

[18] Ghasemi M, Ghavidel S, Ghanbarian MM, Massrur HR, Gharibzadeh M. Application of imperialist competitive algorithm with its modified techniques for multi-objective optimal power flow problem: a comparative study. Inform Sci 2014; 281: 225-47.

[19] Niknam T, Mojarrad HD, Firouzi BB. A new optimization algorithm for multi-objective economic/emission dispatch. Int J Electr Power Energy Syst 2013; 46: 283-93.

[20] Bhattacharjee K, Bhattacharya A, Dey SHN. Solution of economic load dispatch problems of power systems by real coded chemical reaction algorithm. Int J Electr Power Energy Syst 2014; 59: 176-87.

[21] Bornapour M, Hooshmand RA. An efficient scenario-based stochastic programming for optimal planning of combined heat, power, and hydrogen production of molten carbonate fuel cell power plants. Energy 2015; 83: 734-48.

[22] Younes M, Khodja F, Kherfane RL. Multi-objective economic emission dispatch solution using hybrid FFA (firefly algorithm) and considering wind power penetration. Energy 2014; 67: 595-606.

[23] Morshed MJ, Asgharpour A. Hybrid imperialist competitive-sequential quadratic programming (HIC-SQP) algorithm for solving economic load dispatch with incorporating stochastic wind power: A comparative study on heuristic optimization techniques. Energy Convers Manage 2014; 84: 30 - 40.

[24] Ghasemi M, Ghavidel S, Rahmani S, Roosta A, Falah H. A novel hybrid algorithm of imperialist competitive algorithm and teaching learning algorithm for optimal power flow problem with non-smooth cost functions. Eng Appl Artif Intell 2014; 29: 54-69. 
551 [25] Coelho LS, Mariani VC. Combining of chaotic differential evolution and quadratic 552 programming for economic dispatch optimization with valve-point effect. IEEE Trans Power $553 \quad$ Syst 2006; 21(2): $989-96$.

554 [26] Panigrahi BK, Ravikumar Pandi V, Das S, Das S. Multiobjective fuzzy dominance based 555 bacterial foraging algorithm to solve economic emission dispatch problem. Energy 2010; 35: $556 \quad 4761-70$.

557 [27] Hosseinnezhad V, Rafiee M, Ahmadian M, Ameli MT. Species-based quantum particle 558 swarm optimization for economic load dispatch. Int J Electr Power Energy Syst 2014; 63: $311-$ 55922.

560 [28] M. Balasubbareddy, S. Sivanagaraju, Chintalapudi V. Suresh, Multi-objective optimization 561 in the presence of practical constraints using non-dominated sorting hybrid cuckoo search 562 algorithm. Engineering Science and Technology, an International Journal (2015), 563 http://dx.doi.org/10.1016/j.jestch.2015.04.005.

564 [29] Mohseni-Bonab SM, Rabiee A, Mohammadi-Ivatloo B. Voltage stability constrained multi565 objective optimal reactive power dispatch under load and wind power uncertainties: A stochastic 566 approach, Renewable Energy 2016; 85: 598-609.

567 [30] Mahdad B, Srairi K. Differential evolution based dynamic decomposed strategy for 568 solution of large practical economic dispatch. 10th EEEIC International Conference on 569 Environment and Electrical Engineering, Italy, 2011.

570 [31] Azizipanah-Abarghooee R. A new hybrid bacterial foraging and simplified swarm 571 optimization algorithm for practical optimal dynamic load dispatch. Int J Electr Power Energy 572 Syst 2013; 49: 414-29.

573 [32] Bahmani-Firouzi B, Farjah E, Seifi A. A new algorithm for combined heat and power 574 dynamic economic dispatch considering valve-point effects. Energy 2013; 52: 320-32.

575 [33] Jadhav HT, Roy R. Stochastic optimal power flow incorporating offshore wind farm and 576 electric vehicles. Int J Electr Power Energy Syst 2015; 69: 173-87.

577 [34] Ghasemi M, Taghizadeh M, Ghavidel S, A Abbasian A. Colonial competitive differential 578 evolution: An experimental study for optimal economic load dispatch. Appl Soft Comput 2016; 579 40: 342-63. 
581 [35] Foley AM, Gallachóir BPÓ, Hur J, Baldick R, McKeogh EJ. A strategic review of electricity 582 systems models. Energy 2010, 35: 4522-30.

583 [36] Khazali A, Kalantar M. Optimal power flow considering fault current level constraints and 584 fault current limiters. Int J Electr Power Energy Syst 2014; 59: 204-13.

585 [37] Li YZ, Wu QH, Li MS, Zhan JP. Mean-variance model for power system economic 586 dispatch with wind power integrated. Energy 2014; 72: 510-20.

588 Power Energy Syst 2013; 49: 181-7.

589 [39] Basu M. Teaching-learning-based optimization algorithm for multi-area economic dispatch. 590 Energy 2014; 68: 21-8.

591 [40] Manoharan PS, Kannan PS, Baskar S, Willjuice Iruthayarajan M. Evolutionary algorithm 592 solution and KKT based optimality verification to multi-area economic dispatch. Int J Electr 593 Power Energy Syst 2009; 31: 365-73.

594 [41] Sudhakar AVV, Chandram K, Jayalaxmi A, Multi area economic dispatch using secant 595

596 597 598 599 method. J Electr Eng Technol 2013; 8(4): 744-51. [42] Manoharan PS, Kannan PS, Ramanathan V. A novel EP approach for multi-area economic dispatch with multiple fuel options. Turk J Elec Eng \& Comp Sci 2009; 17(1): 1-19.

[43] Singh R, Jain K, Pandit M. Comparison of PSO variants with traditional solvers for large scale multi-area economic dispatch. Chennai and Dr.MGR University Second International Conference on Sustainable Energy and Intelligent System (SEISCON 2011), Dr. M.G.R. University, Maduravoyal, Chennai, Tamil Nadu, India. July2011. 20-22.

603 differential evolution. in Proc. IEEE Int. Conf. Evol. Comput., 1996, pp. 842-844.

604 [45] Storn R, K. V. Price KV. Differential evolution-A simple and efficient heuristics for 605 606 607 608 609 610 global optimization over continuous spaces. J Global Optim 1997; 11(4): 341-59.

[46] Kennedy J, Eberhart RC. Particle swarm optimization. in Proc. IEEE Int. Conf. Neural Netw., Perth, WA, Nov./Dec. 1995, pp. 1942- 1948.

[47] E. Martelli and E. Amaldi, PGS-COM: A hybrid method for con-strained non-smooth blackbox optimization problems: Brief review, novel algorithm and comparative evaluation, Computers and Chemical Engineering 2014; 63, 108-39. 
611 [48] del Valle Y, Venayagamoorthy GK, Mohagheghi S, Hernandez JC, Harley RG. Particle 612 swarm optimization: Basic concepts, variants and applications in power systems. IEEE Trans 613 Evol Comput 2008; 12(2): 171-95.

614 [49] Xin B, Chen J, Zhang J, Fang H, Peng ZH, Hybridizing differential evolution and particle 615 swarm optimization to design powerful optimizers: A review and taxonomy. IEEE Trans Syst 616 Man Cybern C Appl Rev 2012; 42(5): 744-67.

617 [50] Sharma M, Pandit M, Srivastava L. Reserve constrained multi-area economic dispatch 618 employing differential evolution with time-varying mutation. Int J Electr Power Energy Syst $619 \quad 2011 ; 33(3): 753-66$.

620 [51] Sharma M, Pandit M, Srivastava L. Multi-area economic dispatch with tie-line constraints 621 employing evolutionary approach, Int J Eng Sci Technol (IJEST) 2010; 2(3):133 - 50.

622 [52] Alsumait JS, Sykulski JK, Al-Othman AK. Solution of different types of economic load 623 dispatch problems using a pattern search method. Electric Power Compon Syst 2008; 36: 250-6.

624 [53] Wang L, Singh C. Reserve-constrained multiarea environmental/ economic dispatch based 625 on particle swarm optimization with local search. Eng Appl Artif Intell 2009; 22 (2): 298-307.

626 [54] Chen CL, Chen N. Direct search method for solving economic dispatch problem 627 considering transmission capacity constraints. IEEE Trans Power Syst 2001; 16(4): 764-9.

628 [55] Pandit M, Srivastava L, Pal K. Static/dynamic optimal dispatch of energy and reserve using 629 recurrent differential evolution. IET Gener Transm Distrib 2013; 7(12): 1401 - 14.

630 [56] Jeyakumar DN, Jayabarathi T, Raghunathan T. Particle swarm optimization for various 631 types of economic dispatch problems. Int J Electr Power Energy Syst 2006; 28 (1): 36-42.

632

633 [57] Chen CL, Chen ZY, Lee TY. Multi-area economic generation and reserve dispatch 634 considering large-scale integration of wind power. Int J Electr Power Energy Syst 2014; 55: $635 \quad 171-8$. 
[58] Zarei M, Roozegar A, Kazemzadeh R, Kauffmann JM. Two area power systems economic 637 dispatch problem solving considering transmission capacity constraints. Proc. World Academy 638 of Science, Engineering and Technology 2007; 33: 147-52.

639 [59] Fesanghary M, Ardehali MM. A novel meta-heuristic optimization methodology for solving 640 various types of economic dispatch problem. Energy 2009; 34 (6): 757-66.

641 [60] Soroudi A, Rabiee A. Optimal multi-area generation schedule considering renewable 642 resources mix: a real-time approach. IET Gener Transm Distrib 2013; 7 (9): 1011 -26.

643 [61] Yalcinoz T, Short MJ. Neural networks approach for solving economic dispatch problem 644 with transmission capacity constraints. IEEE Trans Power Syst 1998;13(2):307-13.

645 [62] Streiffert D. Multi area economic dispatch with tie line constraints. IEEE Trans Power Syst 646 1995;10(4):1946-51.

647 [63] Lasemi MA, Assili M, Baghayipour M. Modification of multi-area economic dispatch with 648 multiple fuel options, considering the fuelling limitations. IET Gener Transm Distrib 2014; 8 (6): $649 \quad 1098-106$.

650 [64] Wang SK, Chiou J-P, Liu CW. Non-smooth/non-convex economic dispatch by a novel 651 hybrid differential evolution algorithm. IET Gen Transm Distrib 2007;1(5):793-803.

652 [65] Wu YC, Debs AS, Hansen, C. Incorporation of reactive capability curves and area 653 interchanges in multi-area optimal power flow for operator training simulator, Int J Electr Power 654 Energy Syst 2002; 24(2): 131-40.

655 [66] Ahmadi-Khatir A, Conejo AJ, Cherkaoui R. Multi area energy and reserve dispatch under 656 wind uncertainty and equipment failures. IEEE Trans Power Syst 2013; 28 (4): 4373-83.

657 [67] Nogales FJ, Prieto FJ, Conejo AJ. A decomposition methodology applied to the multi area 658 optimal power flow problem. Ann Oper Res 2003; 120 (1): 99-116. 
659 [68]Wang C, Shahidehpour SM. A decomposition approach to nonlinear multi-area generation 660 scheduling with tie-line constraints using expert systems. IEEE Trans Power Syst 1992; 7 (4): 661 1409-18.

662 [69] Helmick SD, Shoults RR. A practical approach to an interim multi-area economic dispatch 663 using limited computer resources. IEEE Trans Power Appl Syst 1985, PAS-104, (6), pp. 1400-4. 664 [70] Suresh CV, Sivanagaraju S, Viswanatha Rao JV. Multi-area multi-fuel economic-emission 665 dispatch using a generalized unified power flow controller under practical constraints. Arab J Sci 666 Eng 2015; 40: 531-49.

667 [71] Jayabarathi T, Sadasivam G, Ramachandran V. Evolutionary programming based multi-area 668 economic dispatch with tie-line constraints. Electr Mach Power Sys 2000; 28 (4): 1165-76.

669 [72] Das S, Suganthan PN, Differential evolution: A survey of the state-of-the-art, IEEE Trans 670 Evol Comput 2011; 15 (1): 4 - 31.

671 [73] Cai Y, Wang J. Differential evolution with hybrid linkage crossover. Inform Sci 2015; 320 672 (1): 244-87.

673 [74] Zhang WJ, Xie XF. DEPSO: Hybrid particle swarm with differential evolution operator. in 674 Proc. IEEE Int. Conf. Syst., Man, Cybern., Washington, DC, Oct. 2003, pp. 3816-21.

675 [75] Hao ZF, Guo GH, H. Huang H. A particle swarm optimization algorithm with differential 676 evolution. in Proc. 6th Int. Conf. Mach. Learn. Cybern., Hong Kong, China, Aug. 2007, pp. $677 \quad 1031-5$.

678 [76] Xu X, Li Y, Fang S, Wu Y, Wang F. A novel differential evolution scheme combined with 679 particle swarm intelligence. in Proc. IEEE Cong. Evol. Comput., Hong Kong, China, Jun. 2008, 680 pp. 1057-62. 
681 [77] Liu S, Wang X, You X. Cultured differential particle swarm optimization for numerical 682 optimization problems. in Proc. Int. Conf. Natur. Comput., Haikou, China, Aug. 2007, pp. 6426838.

684 [78] Jain K, Pandit M. Discussion of "Reserve constrained multi-area economic dispatch 685 employing differential evolution with time-varying mutation’ by Manisha Sharma et al.

686 "International Journal of Electrical Power and Energy Systems”, 33 March (2011) 753-766. Int 687 J Electr Power Energy Syst 2012; 39: 68-9.

688 [79] Zambrano-Bigiarini M, Clerc M, Rojas R. Standard particle swarm optimisa-tion 2011 at 689 EC-2013: a baseline for future PSO improvements, in: 2013 IEEECongress on Evolutionary 690 Computation (CEC), IEEE, 2013, pp. 2337-2344.

691 [80] Jamshid A, Muttaqi KM, Azizi vahed A, Gitizadeh M. Distribution expansion planning 692 considering reliability and security of energy using modified PSO (Particle Swarm Optimization) 693 algorithm. Energy 2014; 65: 398-411.

694 [81] Gitizadeh M, Azizi vahed A, Jamshid A. Multistage distribution system expansion planning 695 considering distributed generation using hybrid evolutionary algorithms. Appl Energy J 2013; 696 101: 655-66. 